جودة الخدمات الطلابية التي تقدمها عمادة شؤون الطلاب بجامعة السلطان قابوس

\author{
وجيهة ثابت العاني * وزهرة بنت ناصر الراسبية
}

جامعة السلطان قابوس، سلطنة عمان

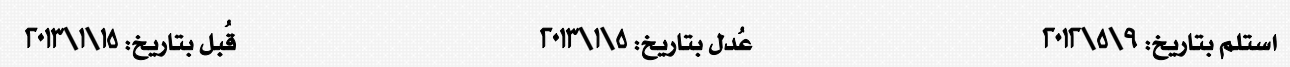

هدفت هذه الدراسة إلى الكشف عن جودة الخدمات الطلابية التي تقدمها عمادة شؤون الطلاب بجامعة السلطان قابوس. وتألفت

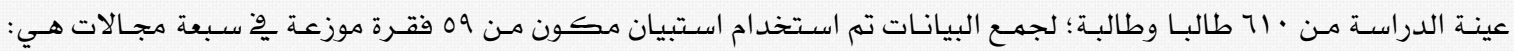

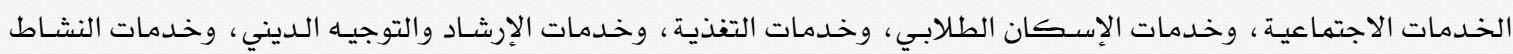

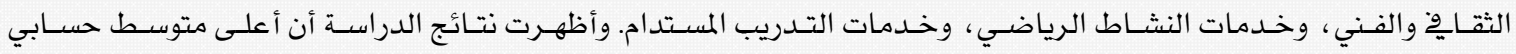

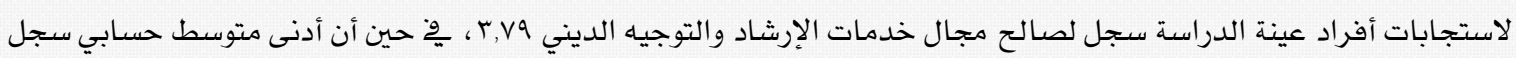

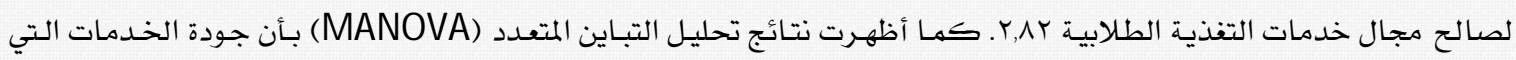

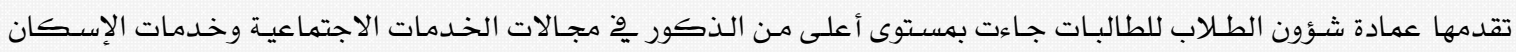

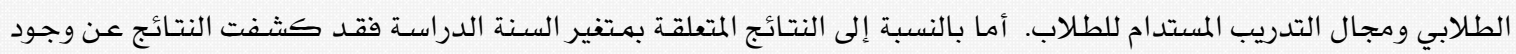

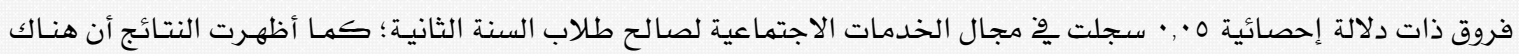

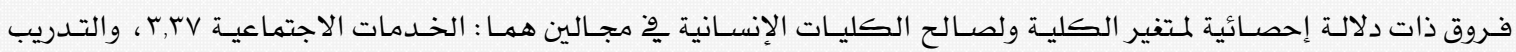

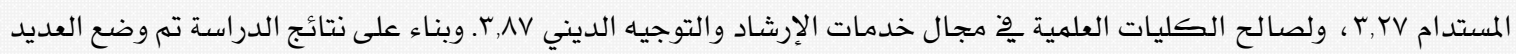
من التوصيات والمقترحات. الكلمات المفتاحية: الخدمات الطلابية، عمادة شؤون الطلاب، الأنشطة الطلابية ، جودة الخدمات.

\title{
The Quality of Student Services Provided by the Deanship of Student Affairs at Sultan Q aboos University
}

\author{
WajehaT. Al-Ani* Zahra N. Al-Rasbiya \\ Sultan Qaboos University, Oman
}

This study aimed to investigate the quality of student services provided by the Deanship of Student Affairs at the Sultan Qaboos University. The study sample consisted of 610 students. Data were collected using a questionnaire consisting of 59 items distributed in seven areas which are: social services, housing services, and food services, and counseling and religious guidance services, cultural and artistic services, sports activities, and sustainable training services. The results showed that the highest mean of the responses is in the counseling and religious guidance 3.79, while the lowest mean is for the area of student food services 2.82.the Results of (MANOVA) showed that the quality of services provided by the Deanship of Student Affairs for students for female was a higher level compared with males in the areas of social services, housing services and sustainable training services. As for the results on the year variable, the result of the study revealed that there are statistically significant differences $(a=0.05)$ related to the field of social services in favor of the second year students. Also the results showed that there are statistically significant differences related to students' points of view in humanities colleges in the areas of social services 3.37, and sustainable training 3.27, while in the area of religious guidance services it is in favor of scientific colleges 3.87. Based on the results of this study, many recommendations and suggestions were developed.

Keywords: student services, dean of student affairs, student activities, quality services.

*wajeha@squ.edu.om 
وتسـعى عـمادة شـؤون الطـلاب هـن خــال دورهــا المســاند

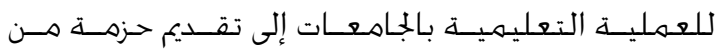

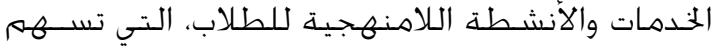

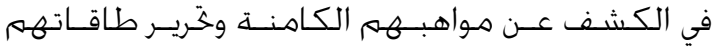

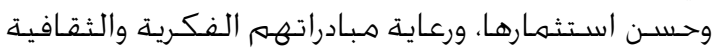

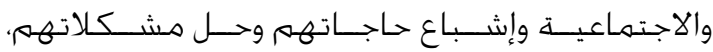

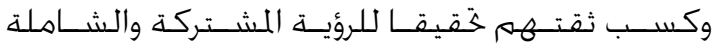

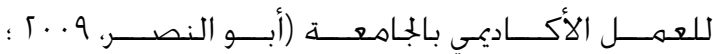

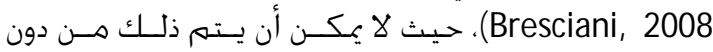

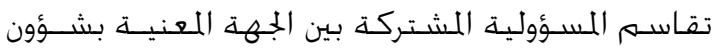

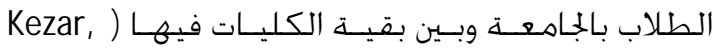
2003

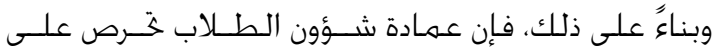

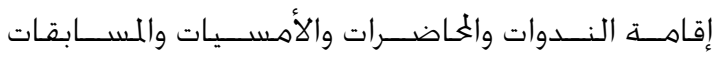

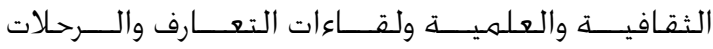

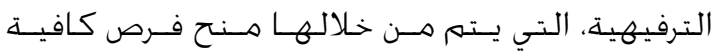

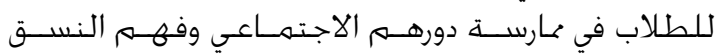

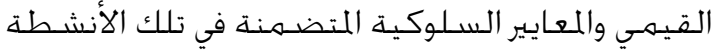

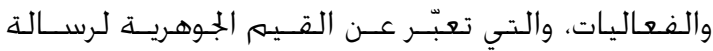

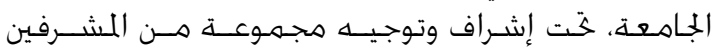

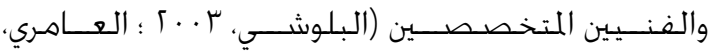

. ( $\Gamma$ r.r

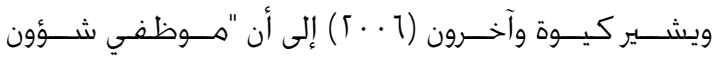

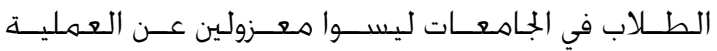

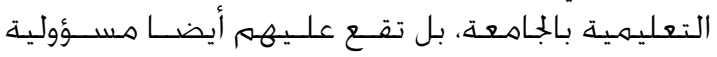

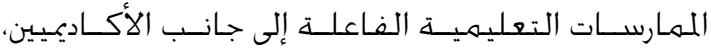

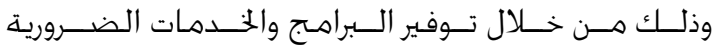

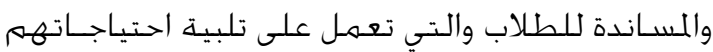

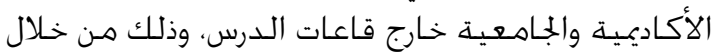

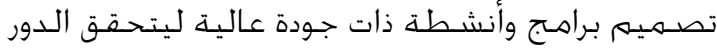

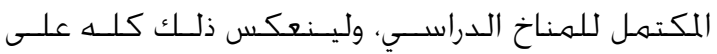

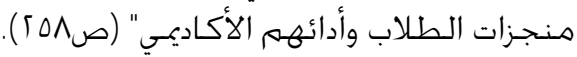
ويمكن الإشـارة هنـا إلى جَربـة جـامعـة ميـامي في الولايـات

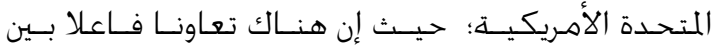

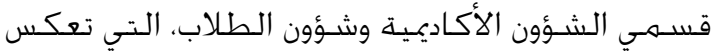

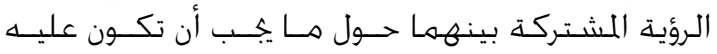

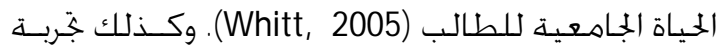

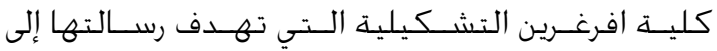

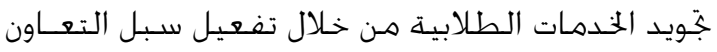

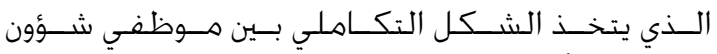

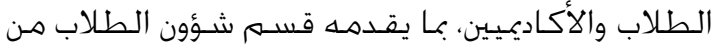

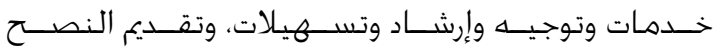

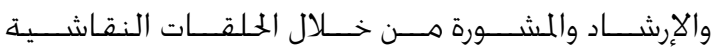
المخصصـة لهـم (كيوة وآخـرون، 1 . . ؟).

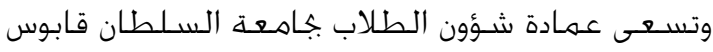

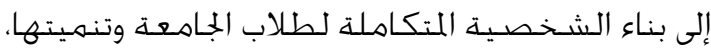

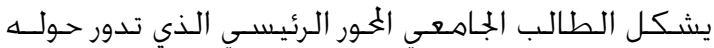

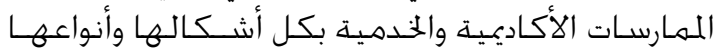

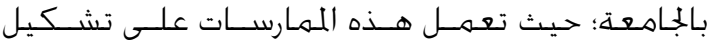

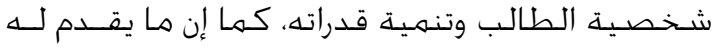

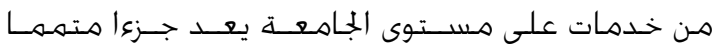

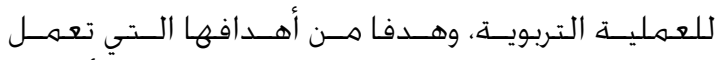
الجامعات على خَقيقهها وتطويرها. وتتعدد صـور وأشـكال

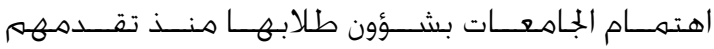

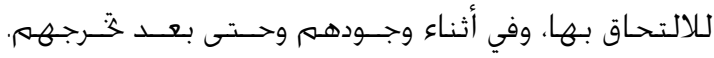

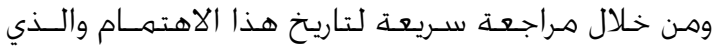

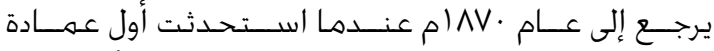

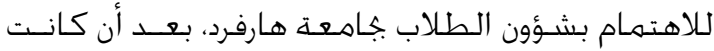

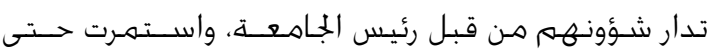

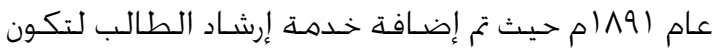
ختت رعاية العمادة (Cutler, 2002).

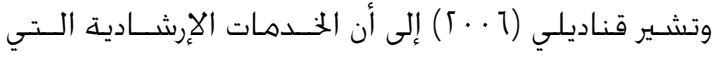

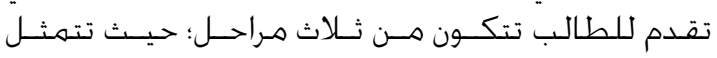

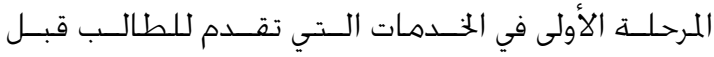

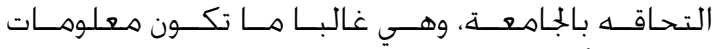

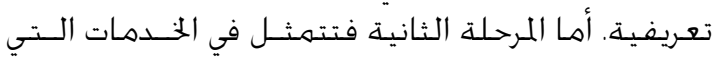

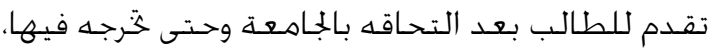

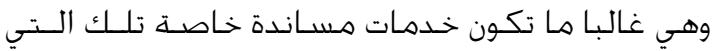

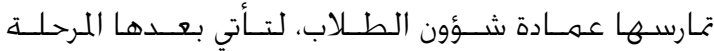

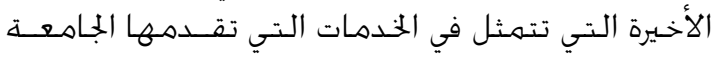

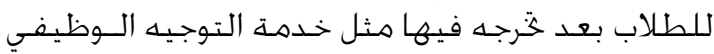

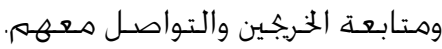

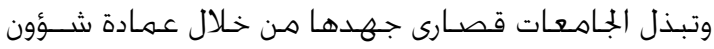

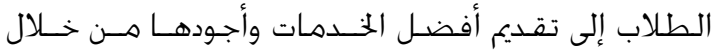

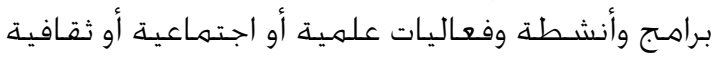

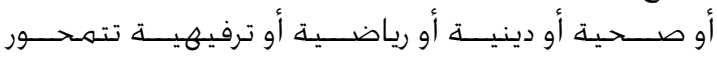

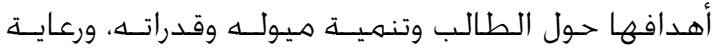

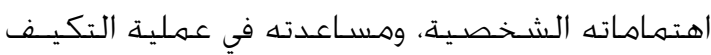

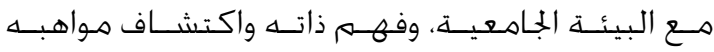

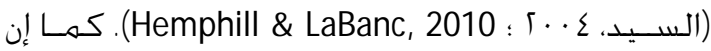

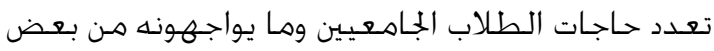

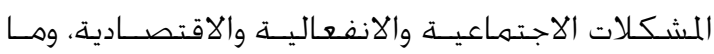

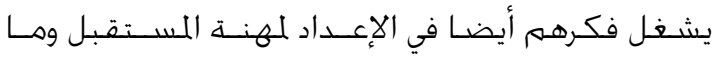

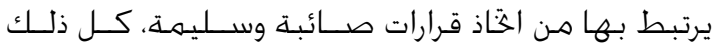

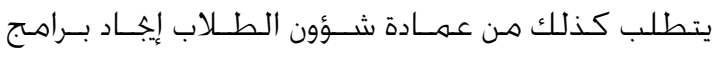

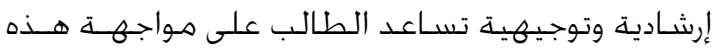

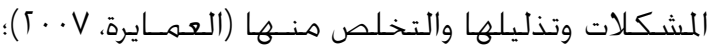

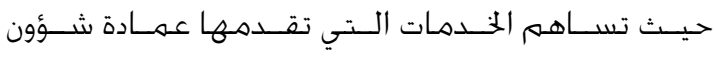

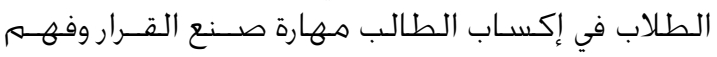

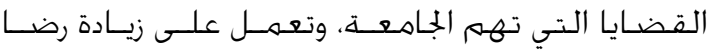

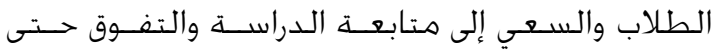

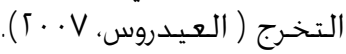




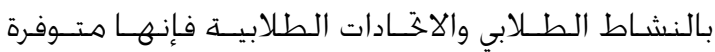

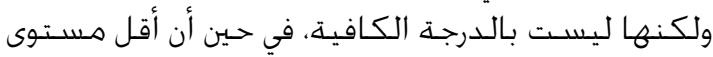

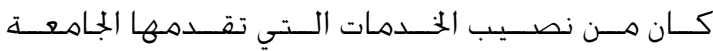

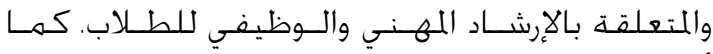

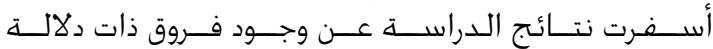

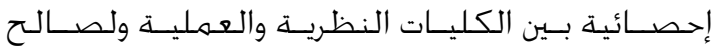

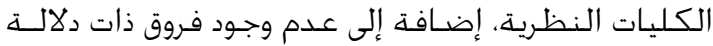
إحصائية تعزى للنوع، ولكان السكن.

أما حول أهمية جودة الخدمات التي تقدمها عمادة

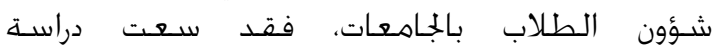
إلى الكشف عن الأسباب (Hutto, \& Fenwick, 2002)

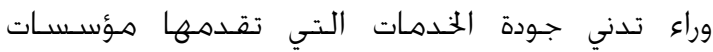

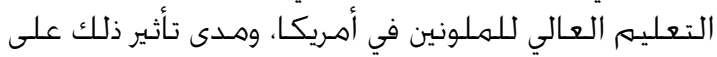

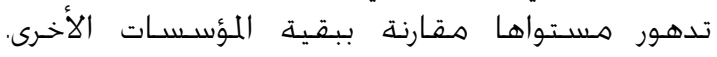

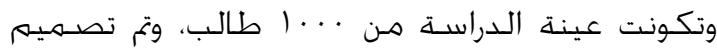
استبانة كأداة رئيسية لجمع البيانات والمعلومات.

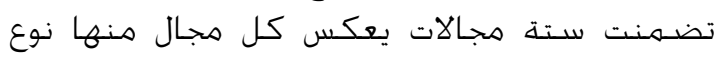
الخدمات التي تقدم للطلاب المتمثلة بالإشراف

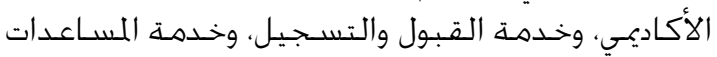

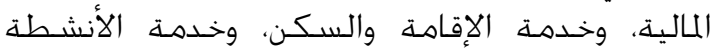

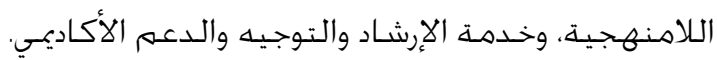

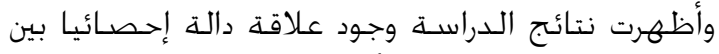
إدراك طالب السنة الأولى لتوافر جودة الخدمات الخات

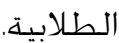

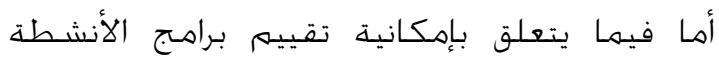

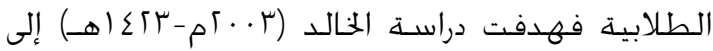

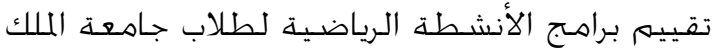

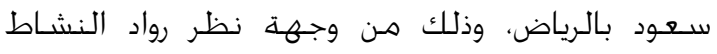

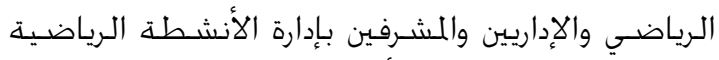

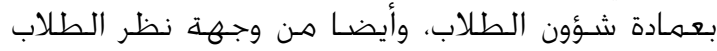
الممارسين لتلك الأنشطة بكليات الجامعة المختلفة.

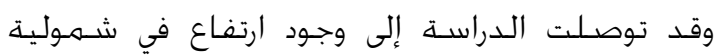

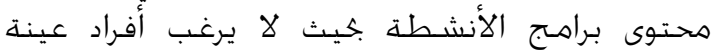

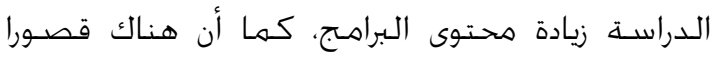

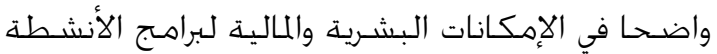

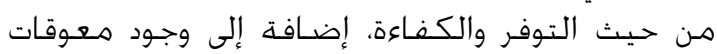

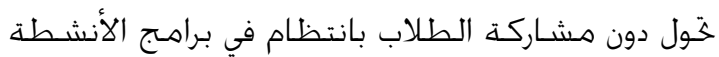
الرياضية.

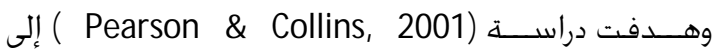

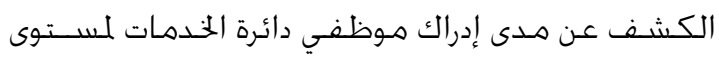

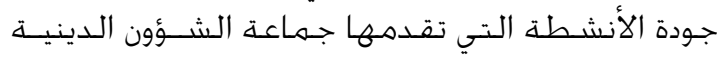

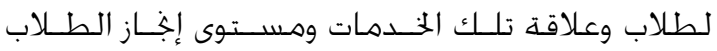

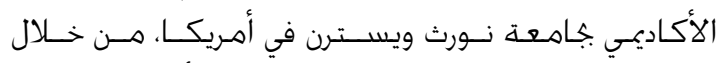

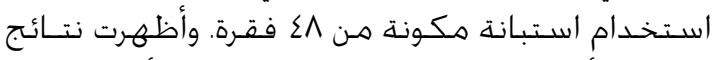

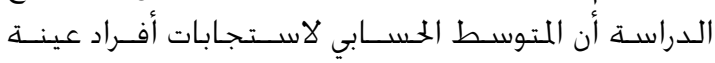

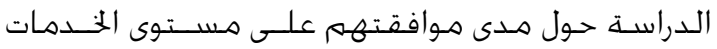

ورعاية مواهبهم وصقلها، وتنمية قدراتهم لتحصـيل

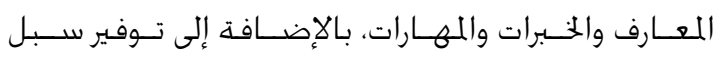

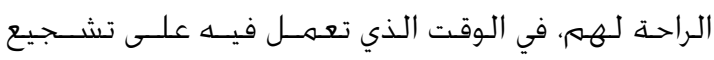

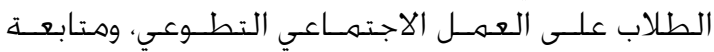

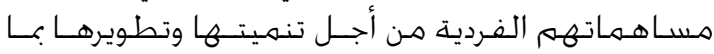

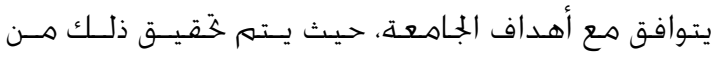

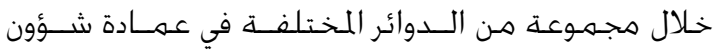

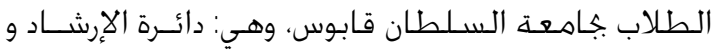

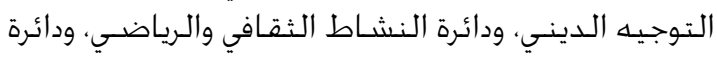

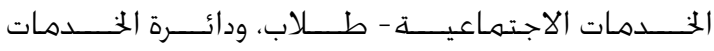

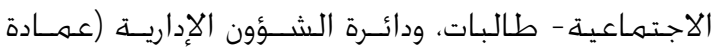

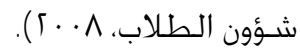

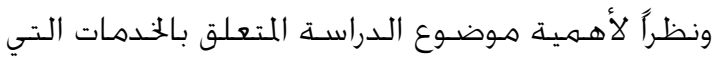

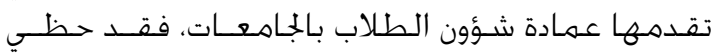

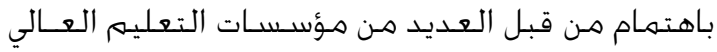

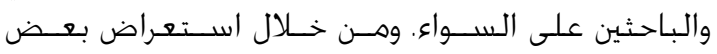

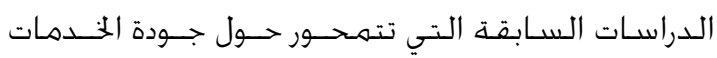
الطلابية التي تقدمها عمادة شـؤون الطلاب بالجامعات:

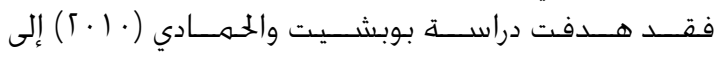

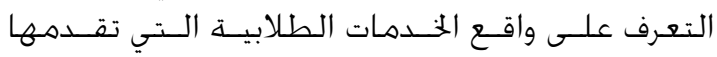

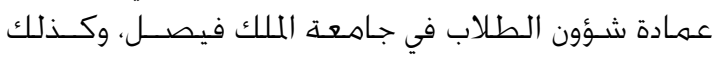

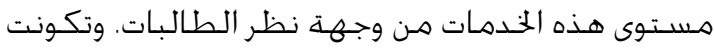

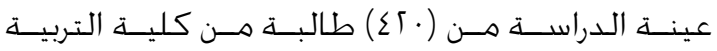

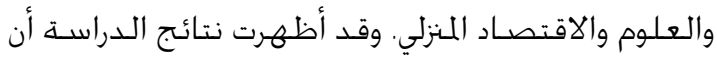

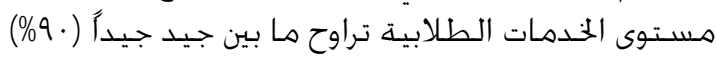

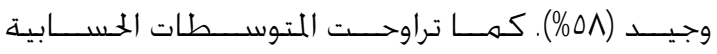

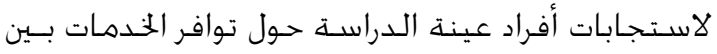

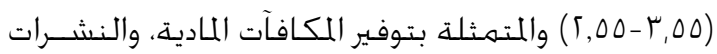

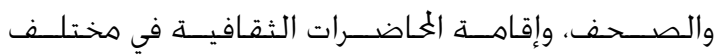

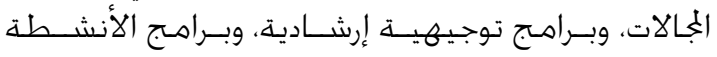

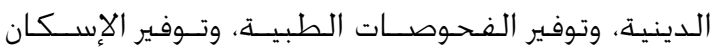

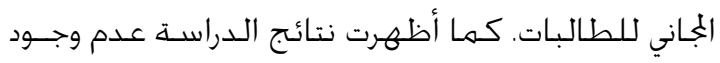

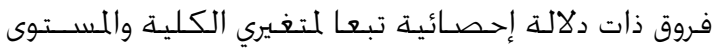

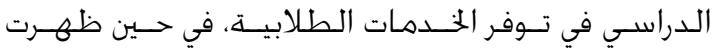

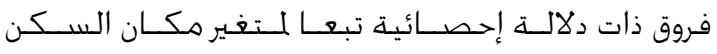

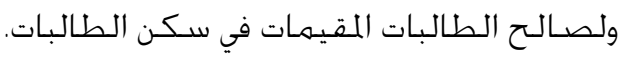

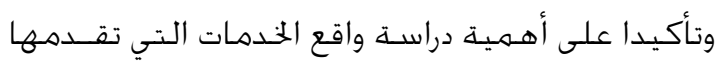

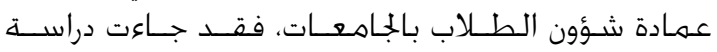

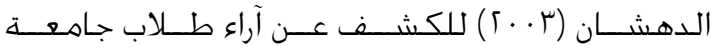

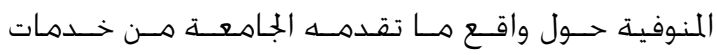

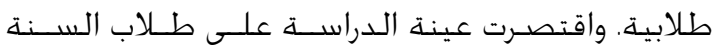

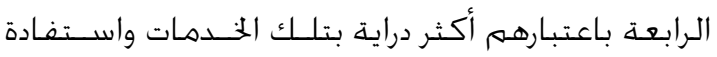

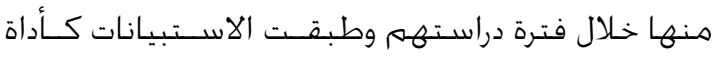

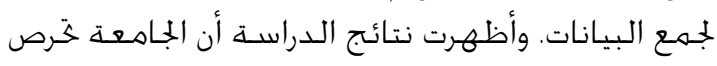

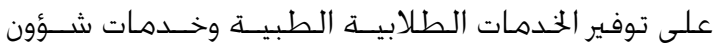

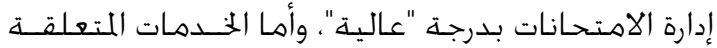


المنشـودة في الارتقاء بمسـتوى أدائها بين الجامعات الأخـرى

$$
\text { وعلى المستويين الإقليهي والعاءلمي. }
$$

\section{تعريف المصطلحات:}

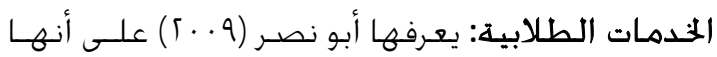

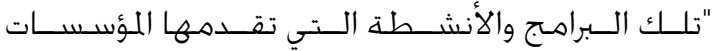
التعليمة لطلابها وذلك بهـدف إشباع حاجـاتهم وحهل

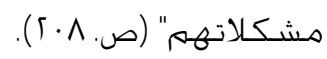

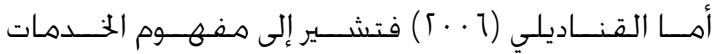

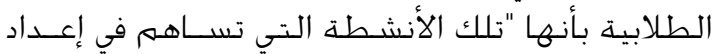

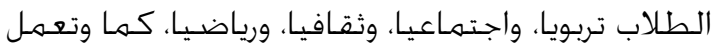

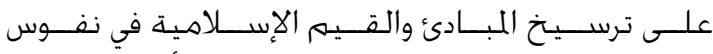

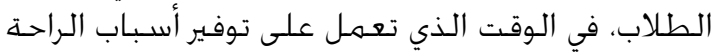

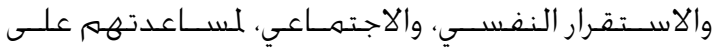

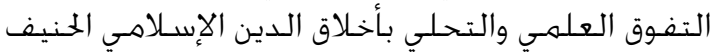

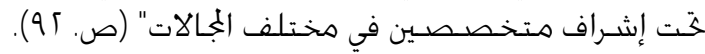
عمادة شؤون الطلاب: هي "الجهة ذات العلاقة المباشرة

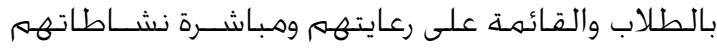

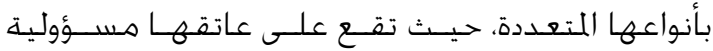

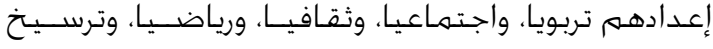

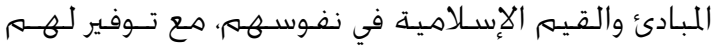

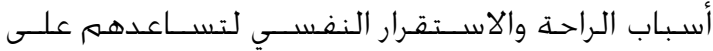

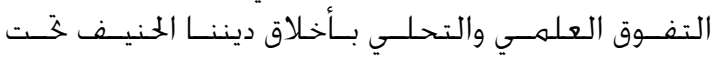

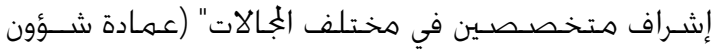

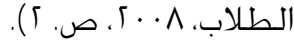

\section{مشكلة الدراسة و أسئلتها:}

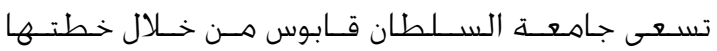

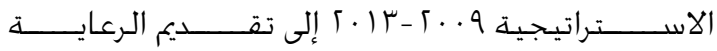

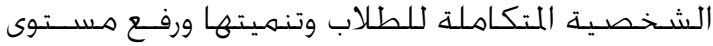

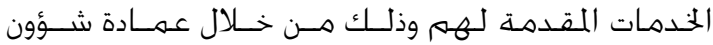

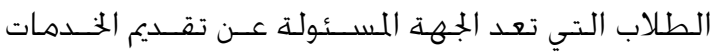

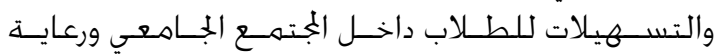

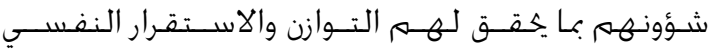

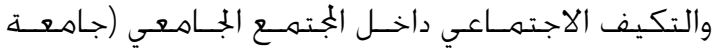

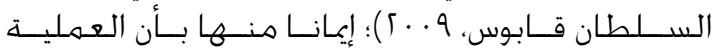

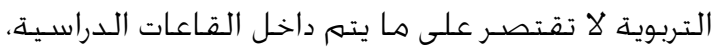

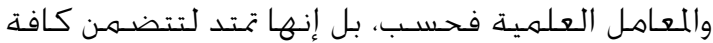

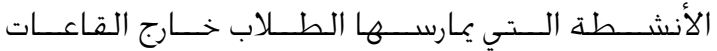

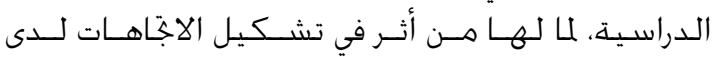

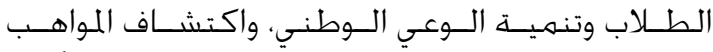

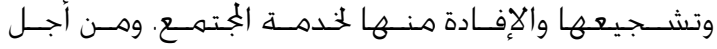

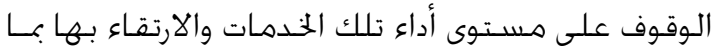

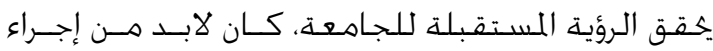

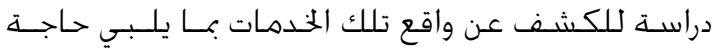

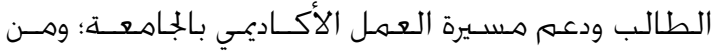
هنا جاءت الدراسـة الحالية لتجبيب عن السـؤالين الآتيين:

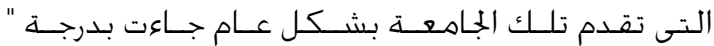

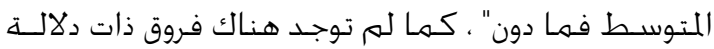

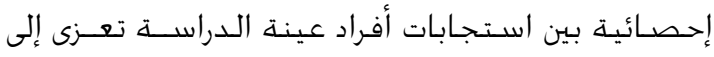

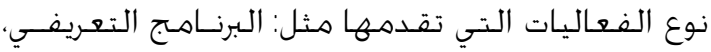

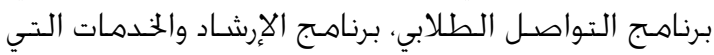
تقدمها دائرة إسكان الطلاب.

وجاءت دراسـة متولي (991 () لتكشـف عن درجــة تقــدير

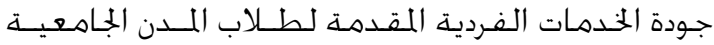

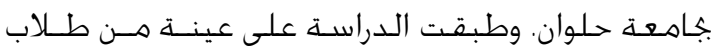

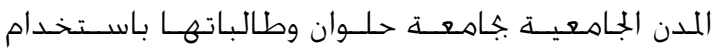
مقياس تضهـن الأبعاد الرئيسـية التالية: المظهر المادي،

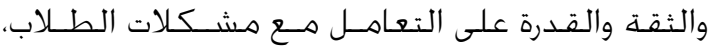

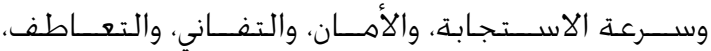

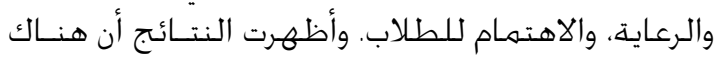

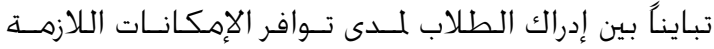

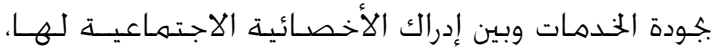

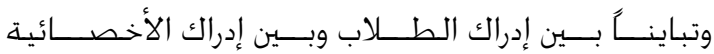

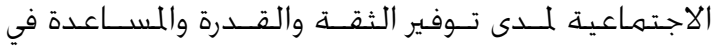
التعامل مع مشكـلات الطلاب.

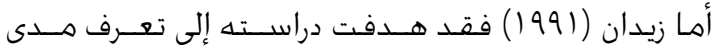

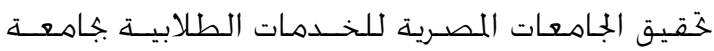

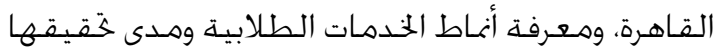

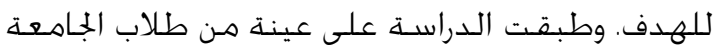

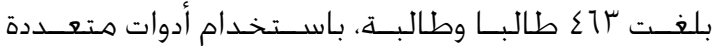

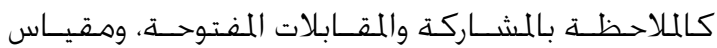

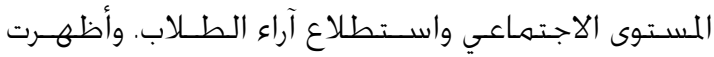

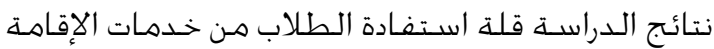

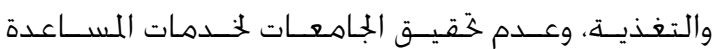

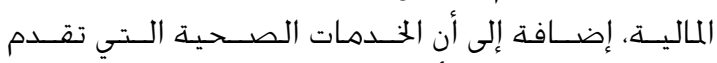
للطلاب غير كافية، وأن الطلاب بحاجة إلى إرشاد وتوجيه الكيه أكاديمي مهني، وديني، واجتماعي على حلٍٍ سـواء.

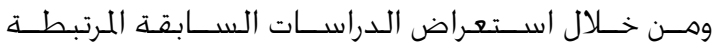

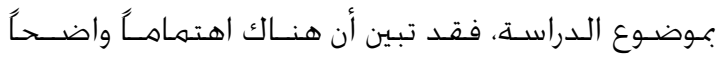

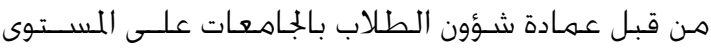

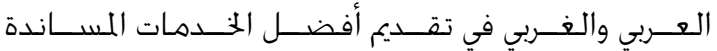

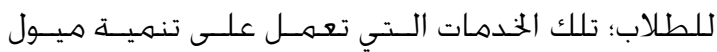

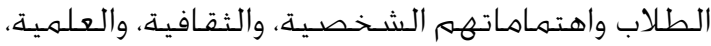
والاجتماعية، وتسعى جامعة السـلطان قابوس -كغيرها

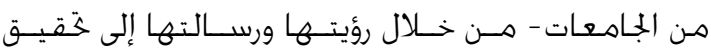

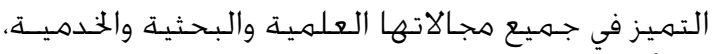

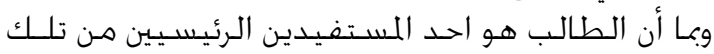

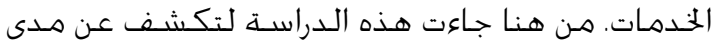

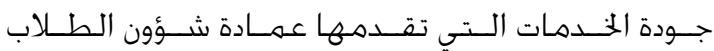

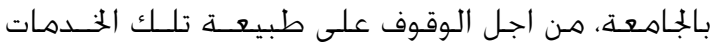

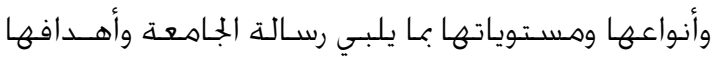




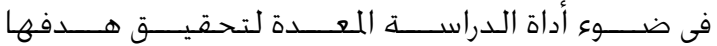

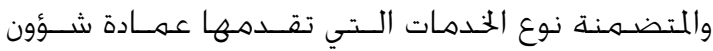

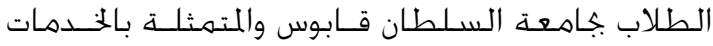

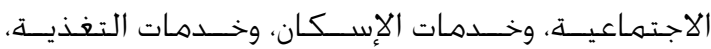

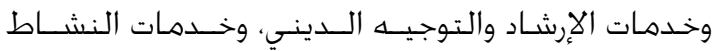

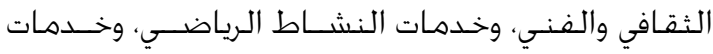
التدريب المستـدام للطلاب. وخدمات ولـات

\section{الطريقة والإجراءات}

\section{مجتمع الدراسة و عينتها:}

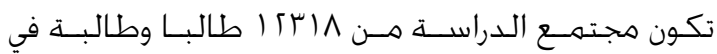

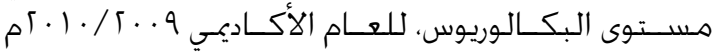

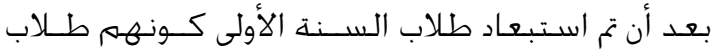

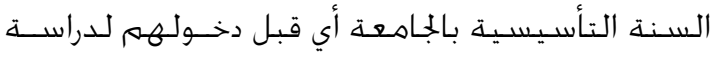

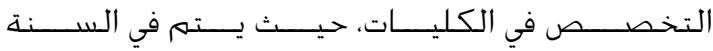

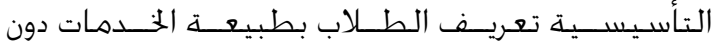

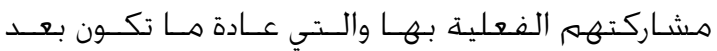

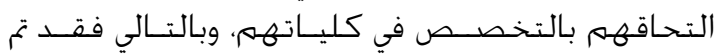

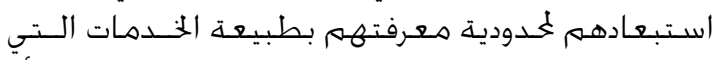

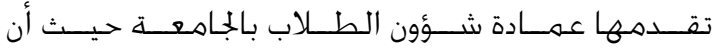

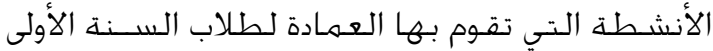

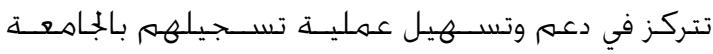

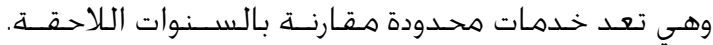

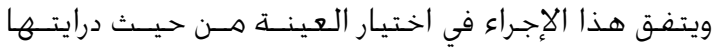

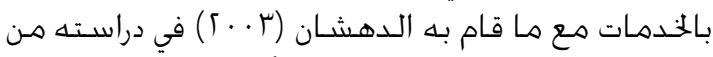

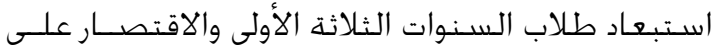

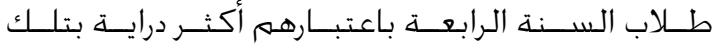
الخدمات.

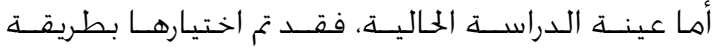

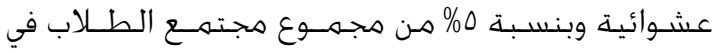

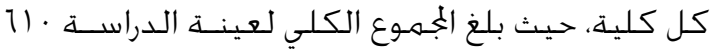

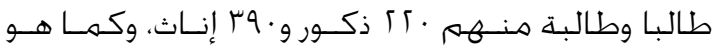

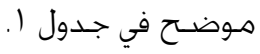

\begin{tabular}{|c|c|c|c|}
\hline \multicolumn{4}{|c|}{ عينة الدر اسة حسب منغير اتها } \\
\hline النسبة & 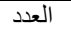 & الفئة & المتغير ات \\
\hline$\%$ \% , 1 & rr. & ذكور & \\
\hline$\% \pi r, q$ & $r q$. & إناث & النوع \\
\hline$\% r_{0}, \varepsilon$ & 100 & الثانية & \\
\hline$\% r \leqslant, T$ & 10. & الثالثة & \\
\hline$\% \curlyvee \uparrow, \wedge$ & IAT & الر ابعة & السنه الدراسية \\
\hline$\% r \cdot, r$ & Kr & الخامسة فأعلى & \\
\hline$\% \leqslant 0, v$ & rVq & كليات العلوم & \\
\hline & & الإنسانية & الكليات \\
\hline$\% 0 \leqslant, r$ & ו וTr & كليات العلوم العلمية & \\
\hline$\% 1 \ldots$ & 71. & & المجموع الكا \\
\hline
\end{tabular}

أداة الدراسة:

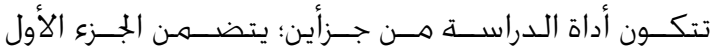

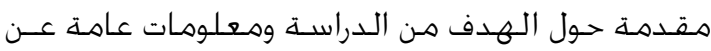

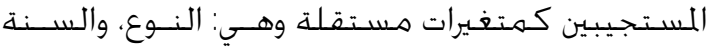

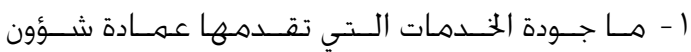

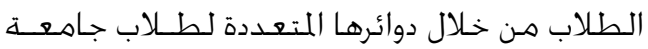

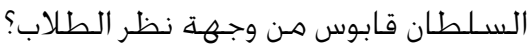

I - هـل توجـد فروق دالــة إحصــائيا في جـودة الخــــــات

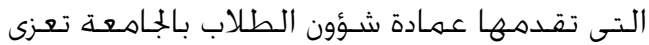

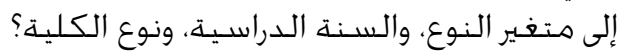

\section{أهداف الدراسة:}

جاءت هذه الدراسـة لتحقيق الأهـداف الآتية: 1 - الكشـف عن درجـة جـودة أداء دوائر وأقسـام عمــادة

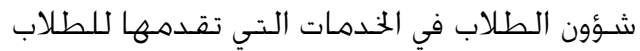
في حياتهم الجامعية.

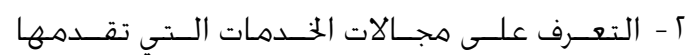

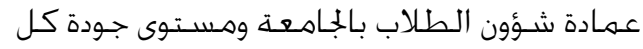

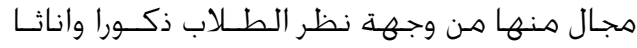
باعتبارهم المستفيدون الرئيسـيون منها.

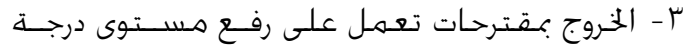

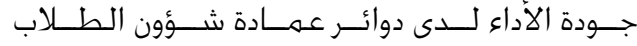
وأقسـامها.

أهمية الدراسة: تتمثل أهـمية الدراســــما يأتي:

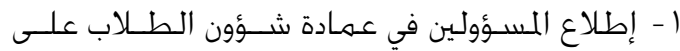

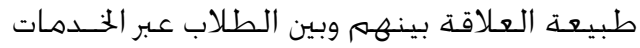

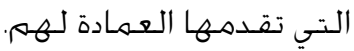

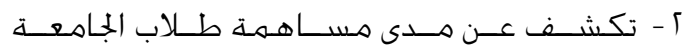

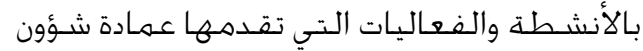
الطلاب.

با - تبين دور عـمادة شـؤون الطــلاب في رعايــة الطــلاب

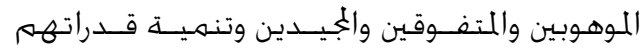
واحتضـان مواهبهـهم. والموفين.

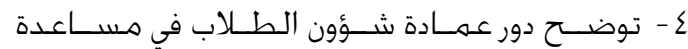

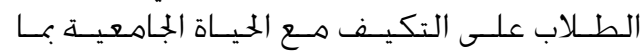

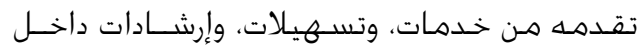

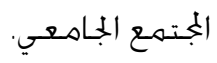
0 - تكشـف عن دور عـمادة شــؤون الطــاب في رعايــــا

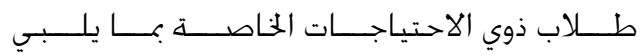
احتياجاتهمه

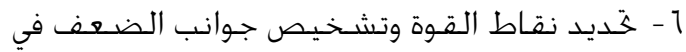

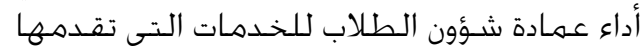
لطلاب الجامعة.

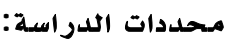

اقتصـرت هذه الدراسـة على عينــة مسن طـلاب جـامعــة

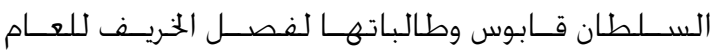

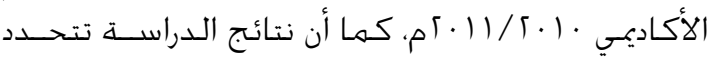




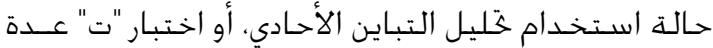
مرات على مسـتوى المتغير الواحدـ.

\section{نتائج الدراسة ومناقشتها}

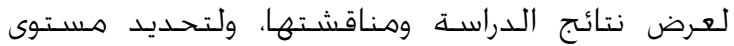

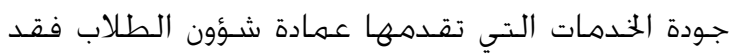

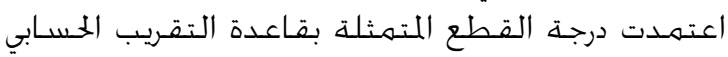
لاستجابات الطلاب وكمها يأتي:

$$
\text { بدرجة بدرجة عالية جداً }
$$

نتائج السـؤال الأول: ما جـودة الخدمات التي تقدمها

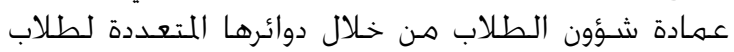

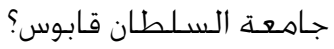

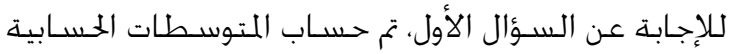

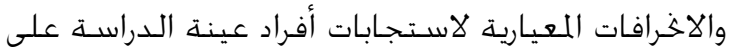

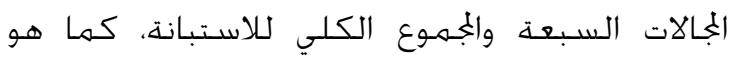

\begin{tabular}{|c|c|c|c|c|c|}
\hline المستوى & المعياري & الحسابي & مجالات الدراسة & $ت$ & الرتبة \\
\hline \multirow[t]{3}{*}{ عالية } & $\cdot, 79$ & $r, v q$ & الإرشاد والتوجيه الديني & $\varepsilon$ & 1 \\
\hline & $\cdot, 14$ & $r, 0 \leqslant$ & خداضمي النشاط & 7 & r \\
\hline & $\cdot, 77$ & $r, \leq \leqslant$ & النشاط الثقافي والفني & $\circ$ & r \\
\hline \multirow[t]{5}{*}{ متوسطة } & $\cdot, 09$ & $r, r)$ & الخدمات الاجتماعية & 1 & $\varepsilon$ \\
\hline & $\cdot, \vee \vee 4$ & $r, 19$ & خدمات الإسكان & r & 。 \\
\hline & $\cdot, \vee \curlyvee$ & $r, 10$ & للطلاب التدريب المستدام & v & 7 \\
\hline & •,Ar & $r, \lambda r$ & خدمات التغذية الطلابية & $r$ & v \\
\hline & .,or & $r, r \leq$ & المجموع الكلي & & \\
\hline
\end{tabular}

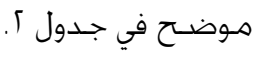

\section{جدول r}

المتوسطات الحسابية والانحرافات المعيارية لاستجابات افراد عينة الدراسة على مجالاتها والمجموع الكلي ومرتبة تنازليا

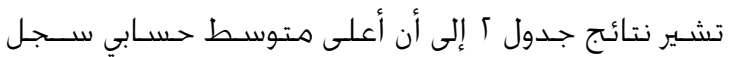

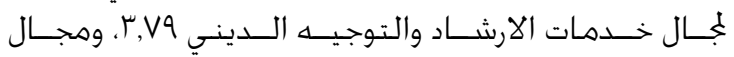

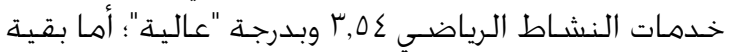

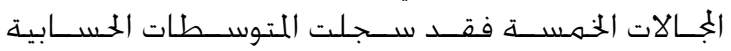

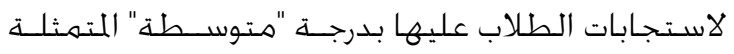

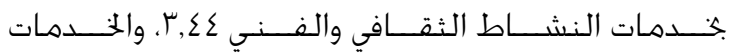

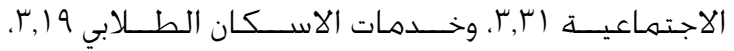

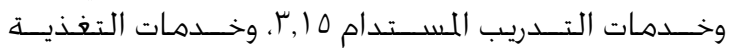

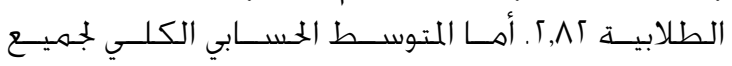

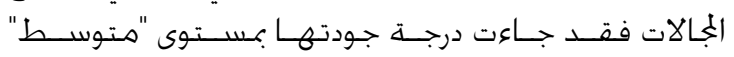

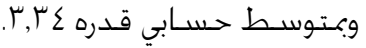

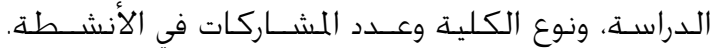

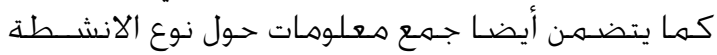

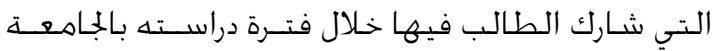

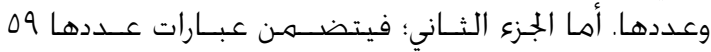

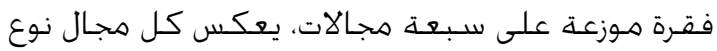

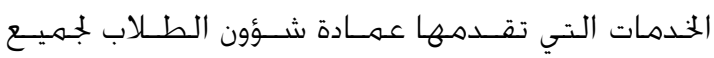

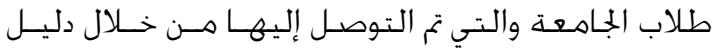

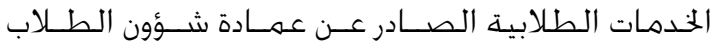

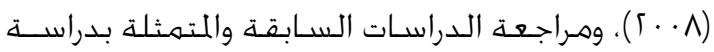

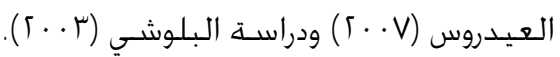

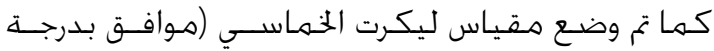

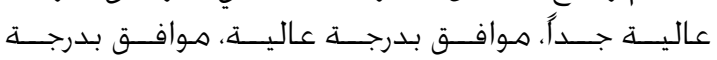

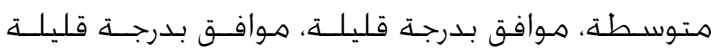

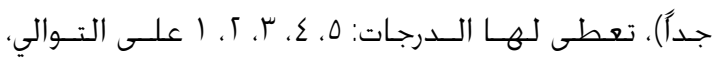

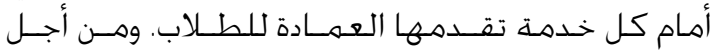

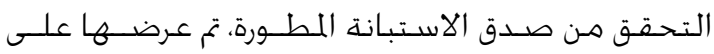

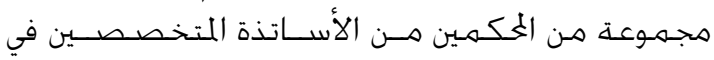

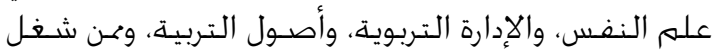

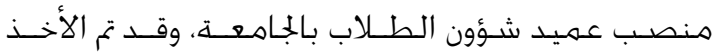

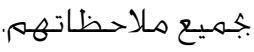

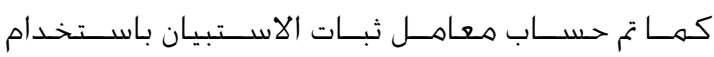

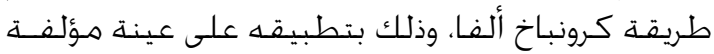

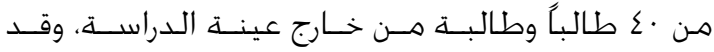

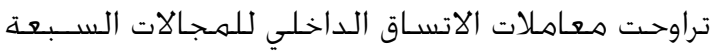

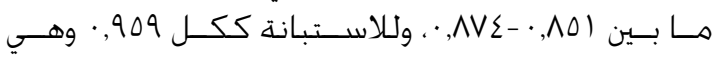

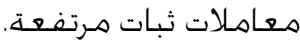
متغـيرات الدراسـة: - مت

$$
\begin{aligned}
& \text { تتبــع الـدراســة المنـهـج الوصــفي، وتتضـمـن الــتغيرات } \\
& \text { الآتيـة: } \\
& \text { ا - متغـير النوع (ذكر، أنثى). }
\end{aligned}
$$

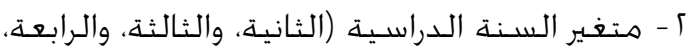

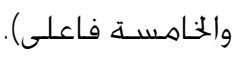

" - متغير الكلية (كليات إنسـانيـة، وكليات علمية).

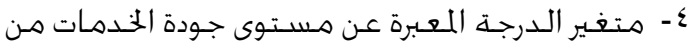

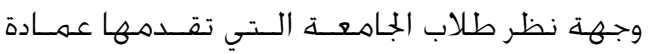
شـؤون الطلاب. الوسـائل الإحصائية

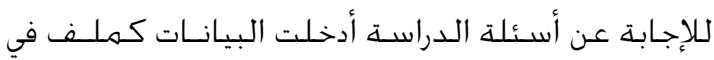

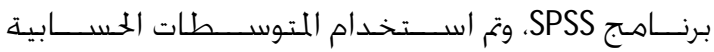

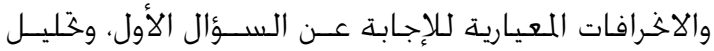

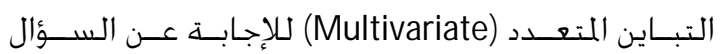

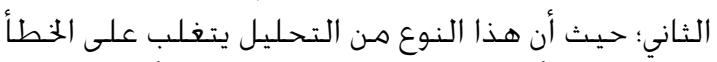

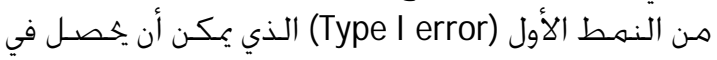


جدول r

المتوسطات الحسابية والاتحرافات المعيارية لاستجابات أفراد عينة الدراسة للفقرات التي حصلت على درجة "عالية" وفقا لمجالاتها

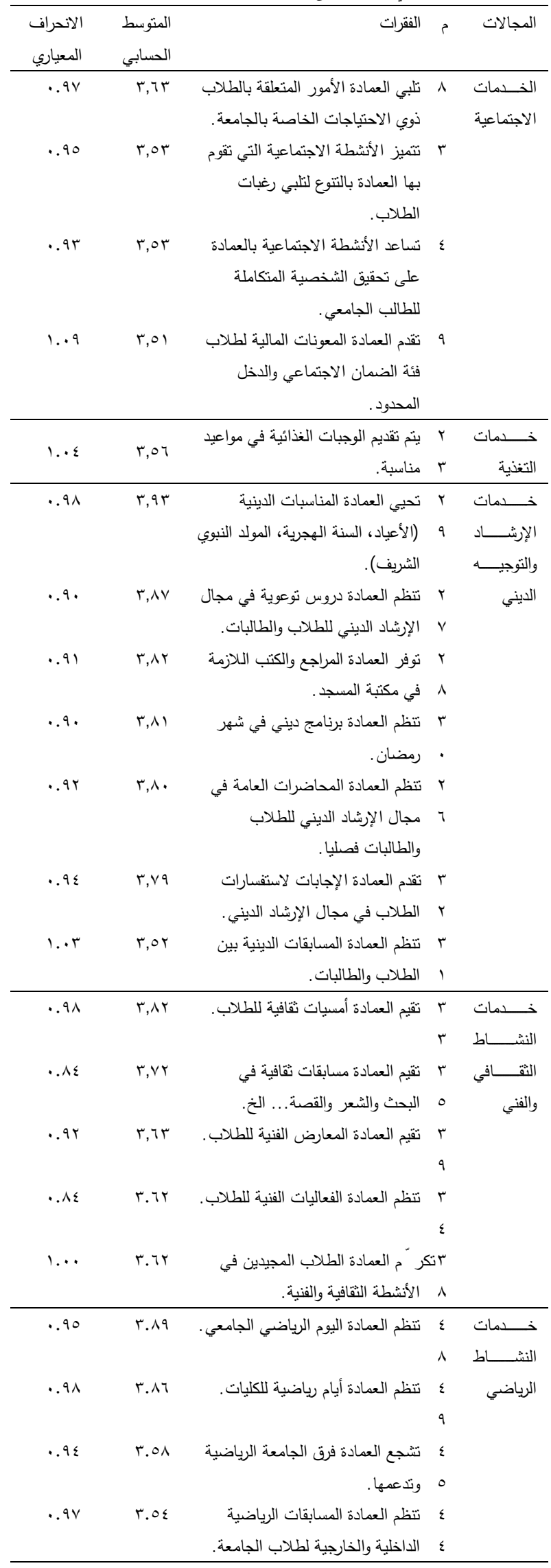

وبما أن أحسد أهداف البحثث هو الوقوف على جهودة الخدمات

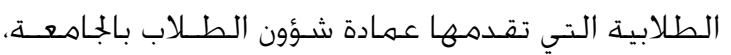

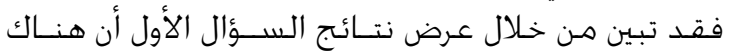

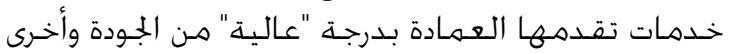

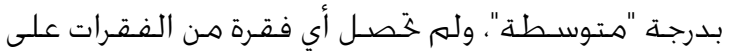

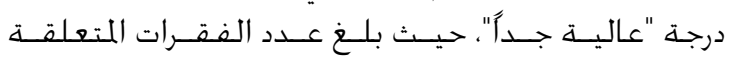

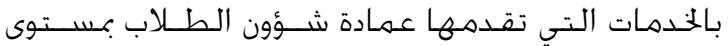

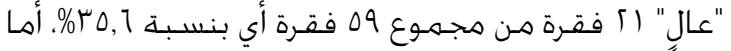

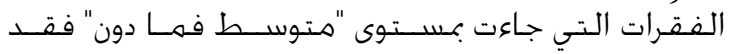

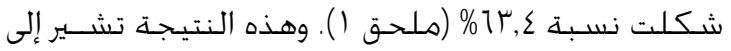

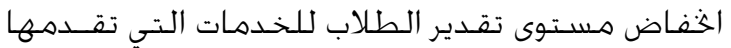

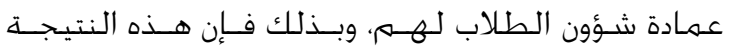

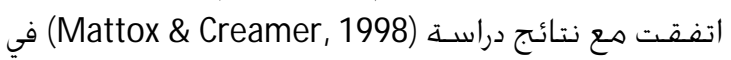

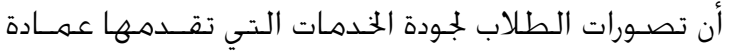

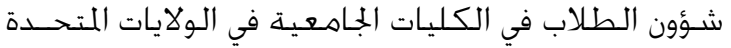

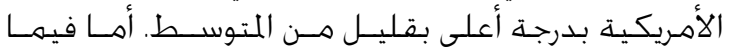

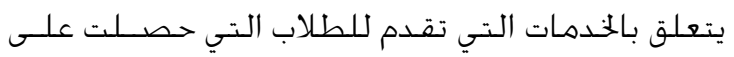

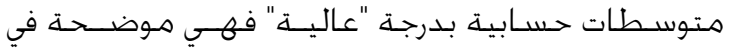

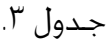

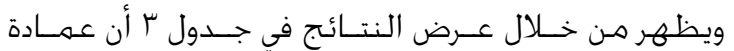

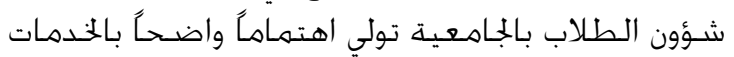

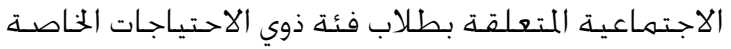

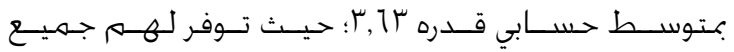

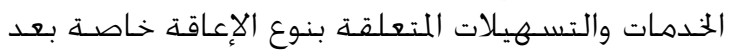

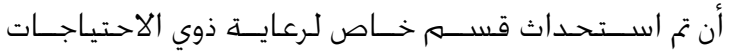

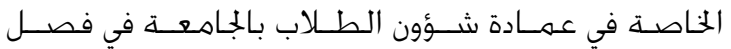

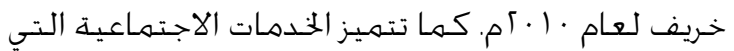

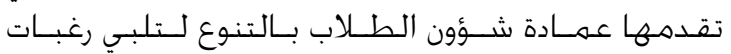

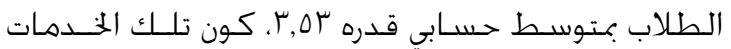

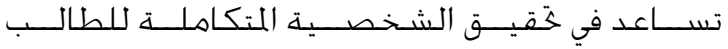

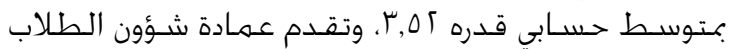

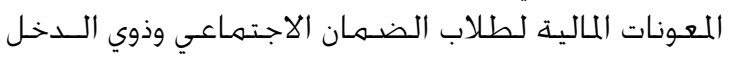

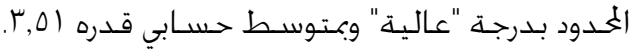

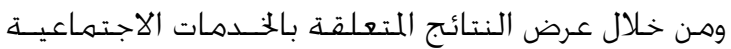

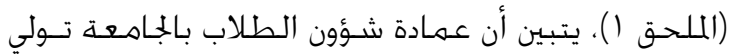

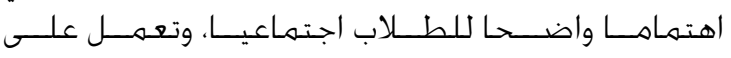

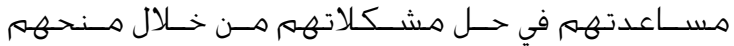

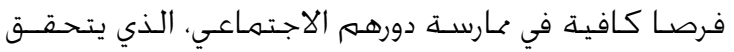

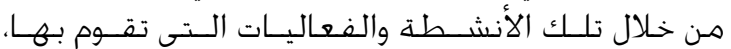

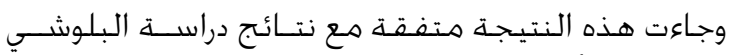

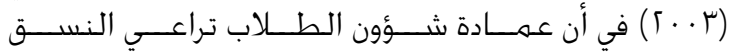

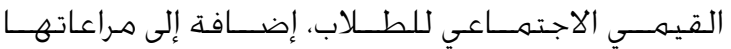

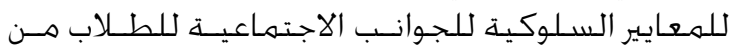
خلال الأنشطة والفعاليات التي تقوم بها. لاجنا. 


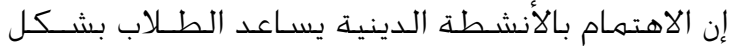

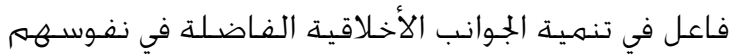

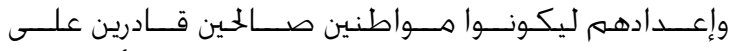

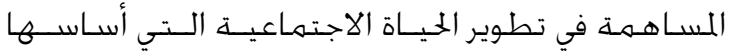
مبادئ الإسـام الحنيف وقيمه الفـاضلة.

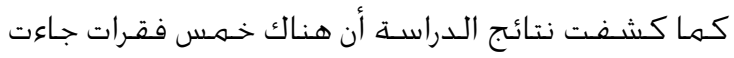

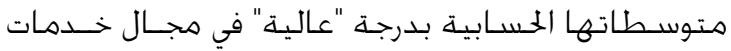

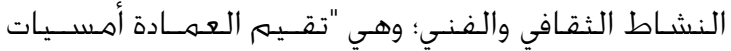

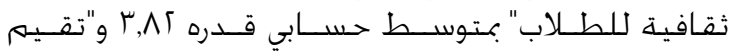

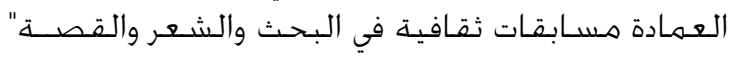

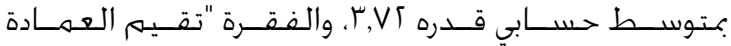

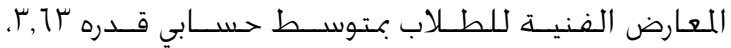

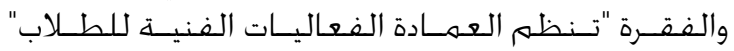

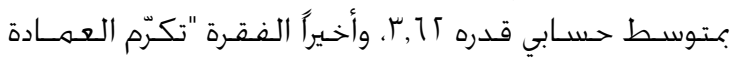

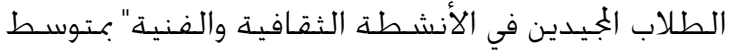

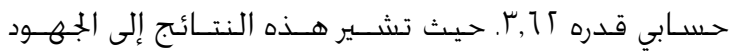

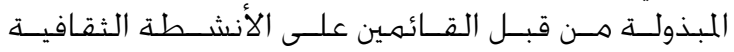

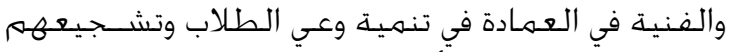

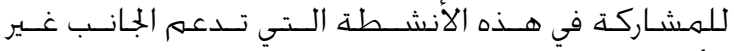

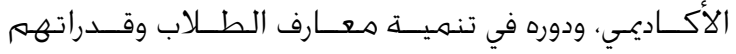

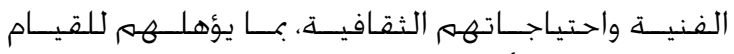

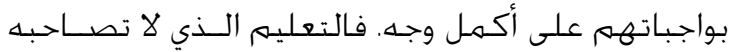

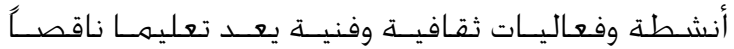

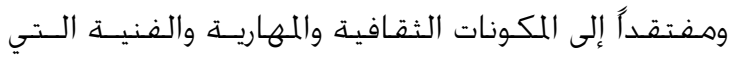

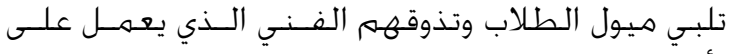

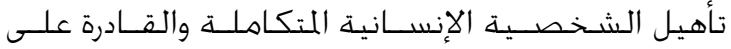

القيام بمتطلبات الحياة بكفاءة واقتدار (السـيد، ع - +).

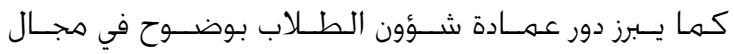

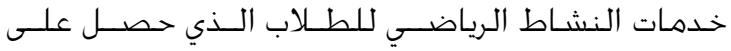

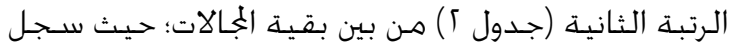

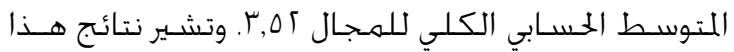

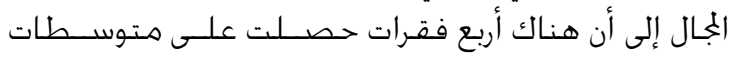

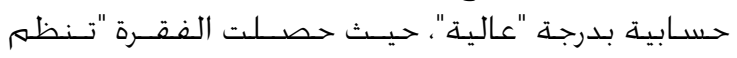

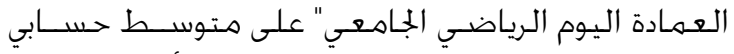

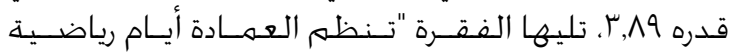

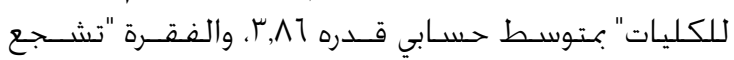

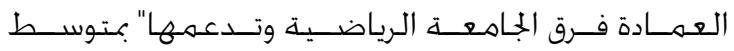

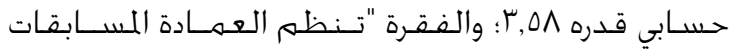

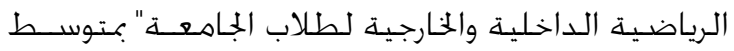

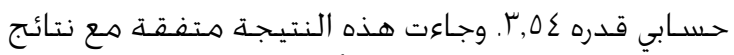

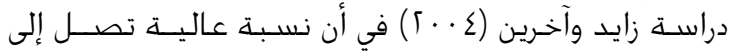

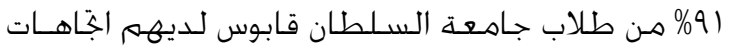

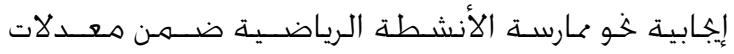

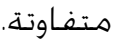

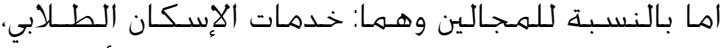

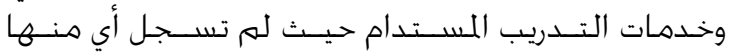

أما بالنسبة إلى خدمات التغذية فقد جاءت المتوســـات المات

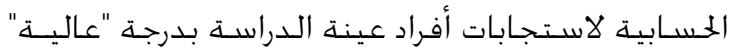

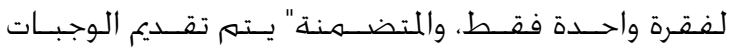

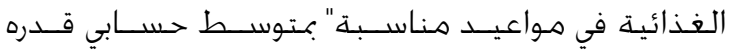

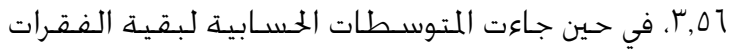

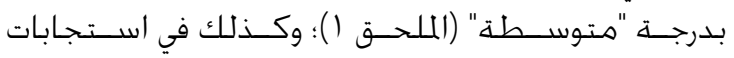

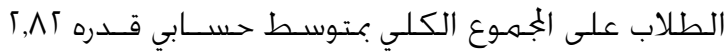

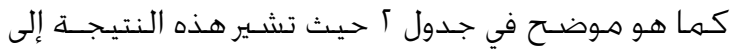

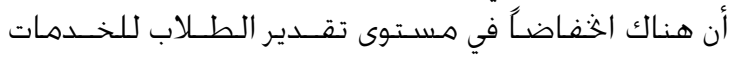

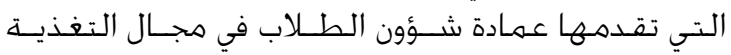

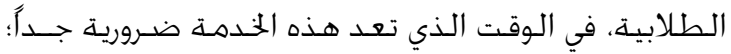

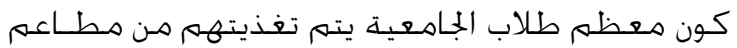

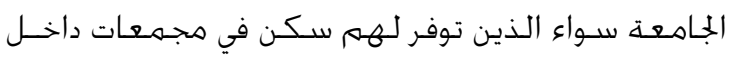

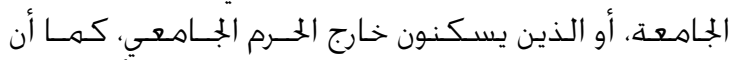

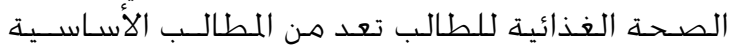

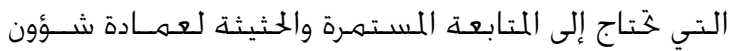

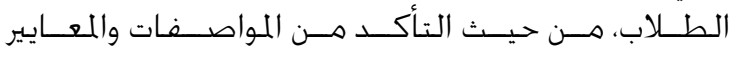

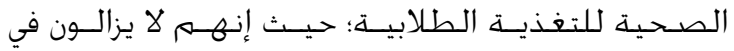

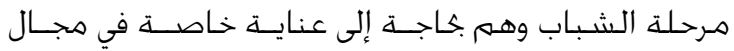

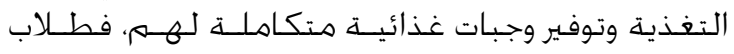

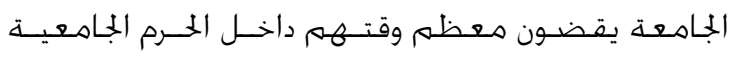

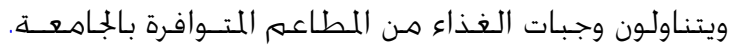

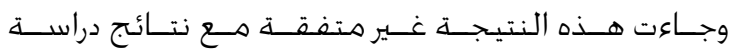

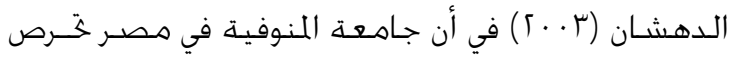

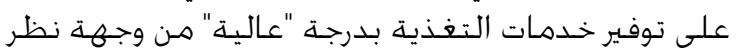
طلابها.

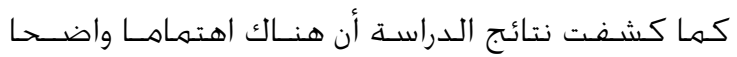

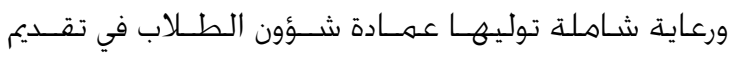

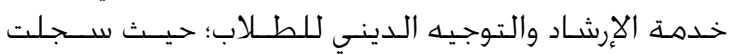

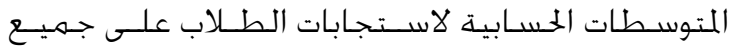

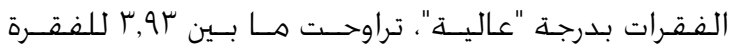

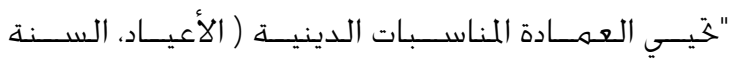

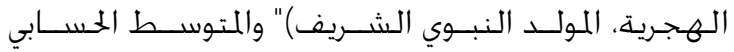

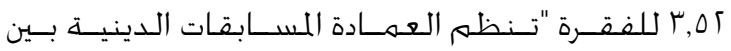

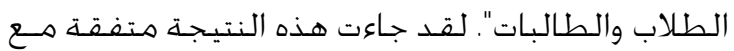

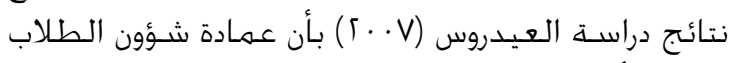

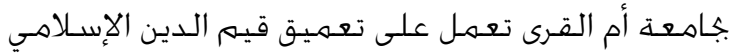

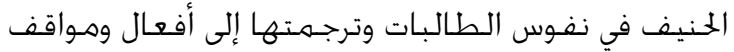

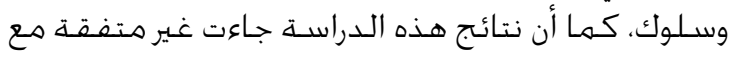

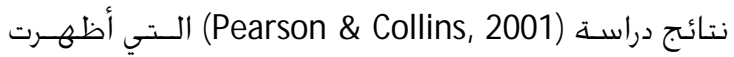

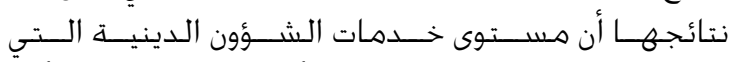

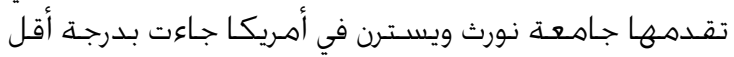

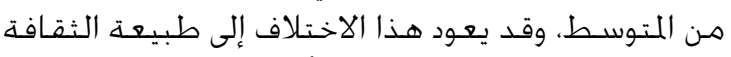

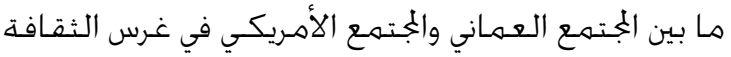

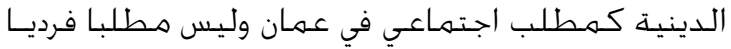
أو شــصيا كما هو في الثقافة الأمريكية. 


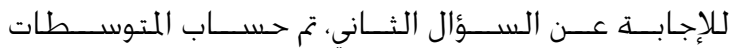

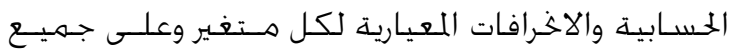

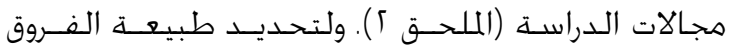
إحصائيًا تم استخـدام خلمليل التباين المتعـدد (MANOVA)

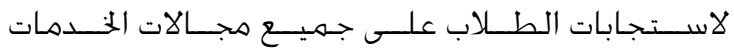

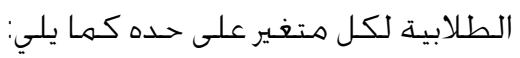

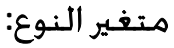

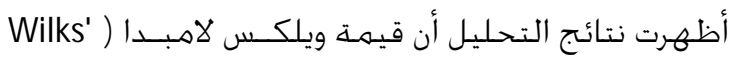
(Lambda

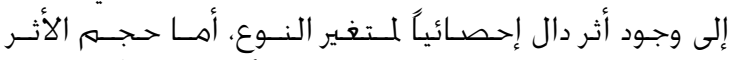

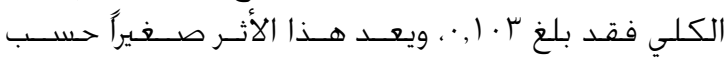
معيار (Cohen, 1988)، وجدول ع يتضـهـن خـلاصـة نتـائج

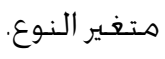

يتضـح مـن جـدول ع أن هنـاك فروقـا ذات دلالـــة إحصــائية

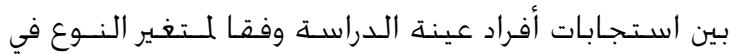

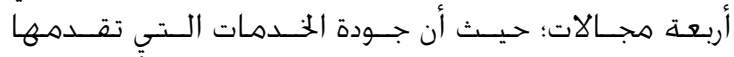

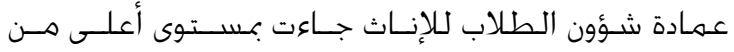

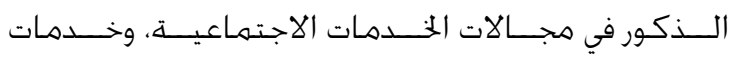

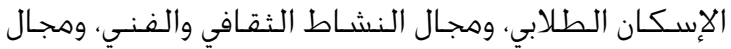

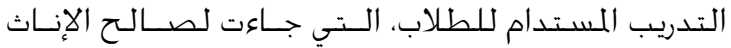

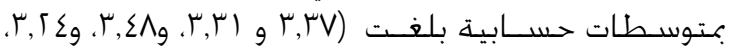

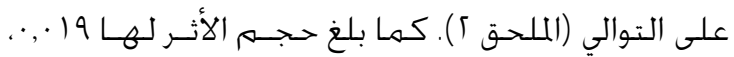
(Cohen

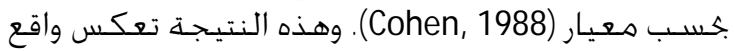

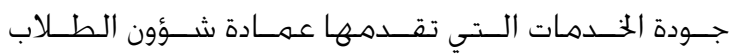

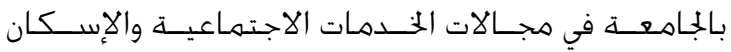

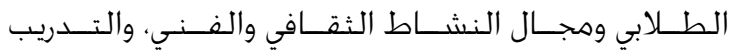

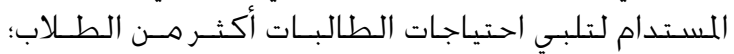

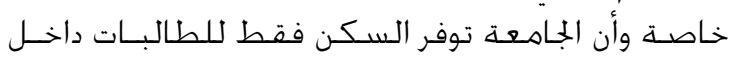

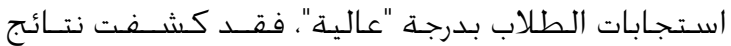

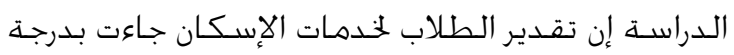

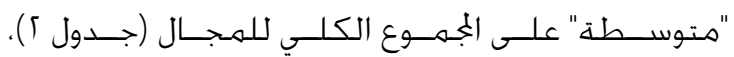

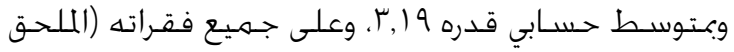

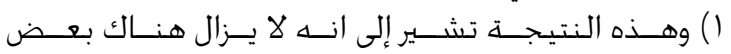

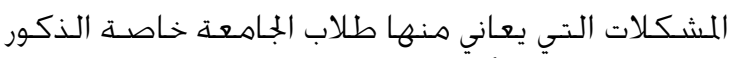

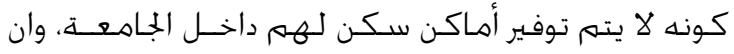

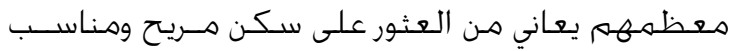
خارج الجامعـة.

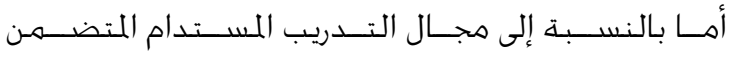

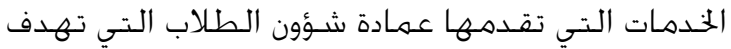

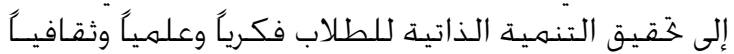

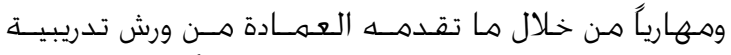

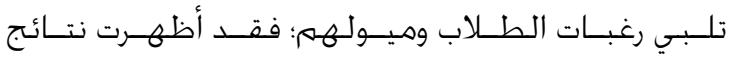

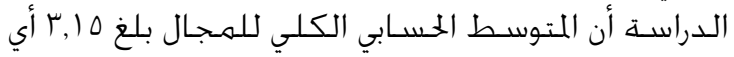

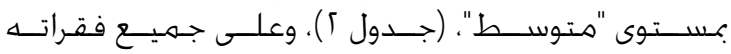

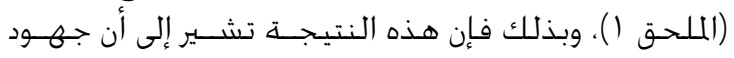

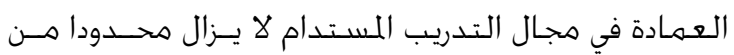

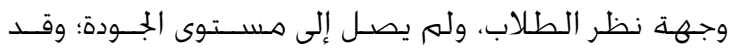

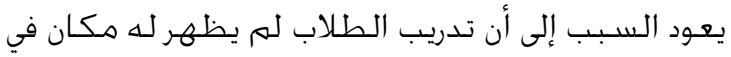

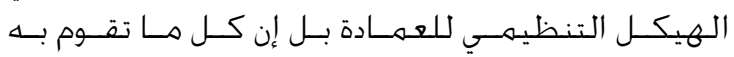

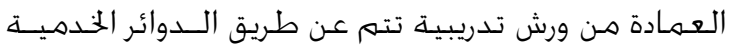

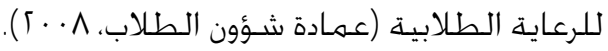

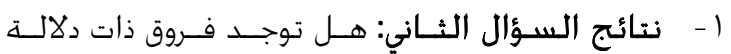

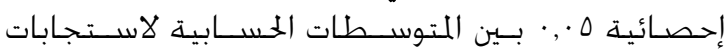

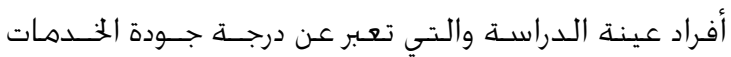

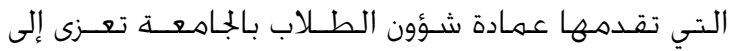

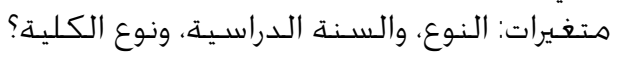

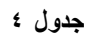

نتائج تحليل التباين المتعدد لاستجابات أفراد عينة الدراسة على جميع مجالاتها وفقاً لمتغير النوع

\begin{tabular}{|c|c|c|c|c|c|c|c|}
\hline حجم الأثر & الدلالة الإحصائية & قالمحسوبة "ف" & متوسط المربعات & درجة الحرية & مجموع المربعات & مجالات الدراسة & مصدر \\
\hline$\cdot, .19$ &,,$\ldots 1$ & $11, V \leq \varepsilon$ & $\varepsilon, \cdot Y Y$ & 1 & $\varepsilon, \cdot r r$ & الخدمات الاجتماعية & النوع \\
\hline$\cdot, \cdot \leq \vee$ & $\cdot, \cdots$ & $r \cdot, r \vee q$ & $17, \wedge r q$ & 1 & $17, \wedge r q$ & خدمات الإسكان الطلابي & \\
\hline .,.,r & $\cdot, r \cdot$ & $1,7 \leqslant \varepsilon$ & $1,11 \leq$ & 1 & $1,11 \leqslant$ & خدمات التخذية الطلابية & \\
\hline , , . r & •, lor & r,.or & $\cdot, 9 \wedge r$ & 1 & •, 9Ar & الإرشاد والتوجيه الديني & \\
\hline$\cdot, \cdots \vee$ & , , tho & $\{, \leqslant 7 \leqslant$ & (1, (1) & 1 & 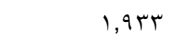 & النشاط الثقافي والفني & \\
\hline , , , r & דוזיו & $1, \varepsilon \cdot 9$ & $\cdot$, TOV & 1 & $\cdot, 70 \mathrm{~V}$ & خدمات النشاط الرياضي & \\
\hline \multirow[t]{8}{*}{$\cdot, \cdot Y \varepsilon$} & $\cdot, \cdots$ & $1 \leqslant, 701$ & $\Lambda, I V \vee$ & 1 & $\wedge, I \vee V$ & التدريب المستدام للطلاب & \\
\hline & & & $\cdot r \leqslant r$ & 7.1 & $r \cdot 1,190$ & الخدمات الاجتماعية & الخطأ \\
\hline & & & $\cdot, 004$ & $7 \cdot 1$ & TrA,Iro & خدمات الإسكان الطلابي & \\
\hline & & & $\cdot, T \vee \wedge$ & $7 \cdot 1$ & $\varepsilon \mid r, \cdot \wedge r$ & خدمات التخذية الطلابية & \\
\hline & & & $\cdot, \leqslant \vee 9$ & 7.1 & $r q \cdot, q q r$ & الإرشاد والتوجيه الديني & \\
\hline & & & ( & 7.1 & rTr,rth & النشاط الثقافي والفني & \\
\hline & & & $\cdot, \leq 74$ & $7 \cdot 1$ & rAT, rV & خدمات النشاط الرياضي & \\
\hline & & & $\cdot, 001$ & 7.1 & $r r q, r q$. & التدريب المستدام للطلاب & \\
\hline
\end{tabular}


أظهرت نتائج التحليل أن قيمة ويلكـس لامبــا ( 'Wilks' (Lambda

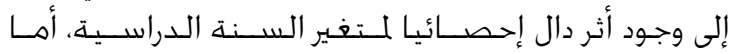

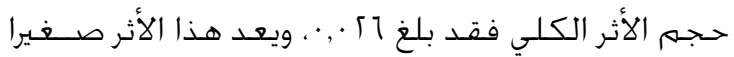
حسب معيار (Cohen, 1988)، وجدول ه يوضـح ذلك.

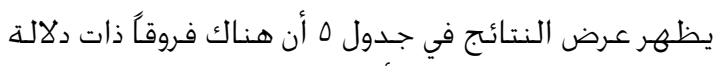

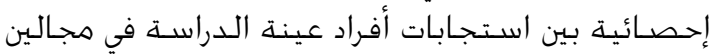

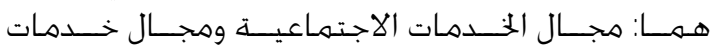

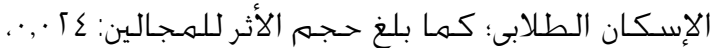

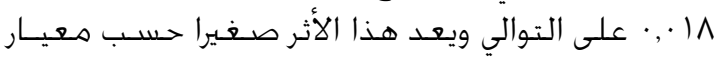
(Cohen, 1988)

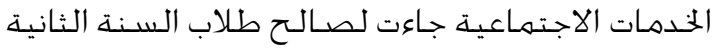

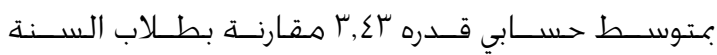

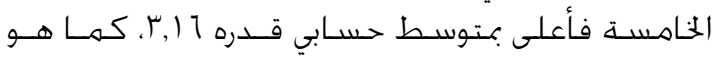

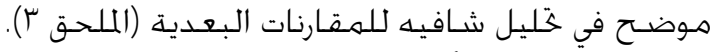
ويككن تفسيرير ذلك بأن الخدمات الاجتماعية التي توفرها

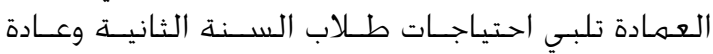

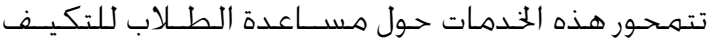
هع مستجدات الحياة الأكاديمية بالجامعة. مدادة

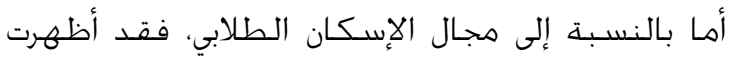

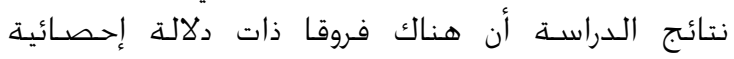

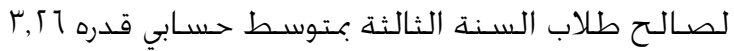

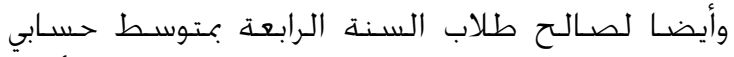

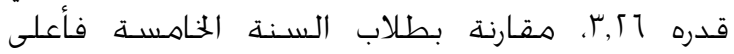

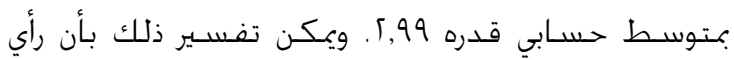

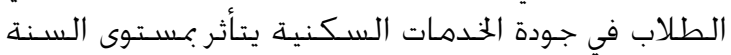

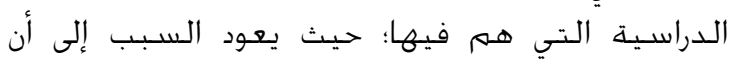

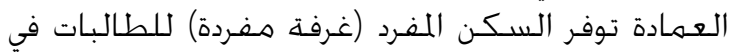

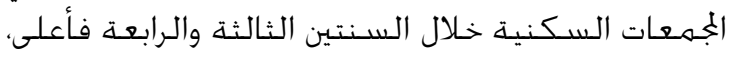

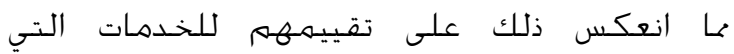

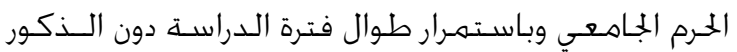

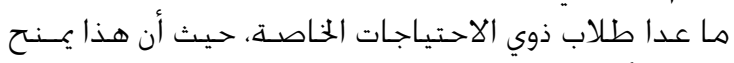

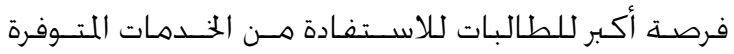

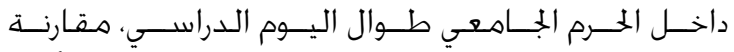

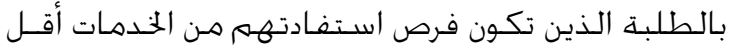

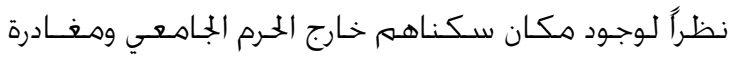

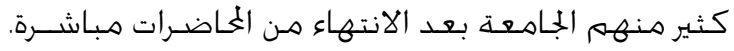

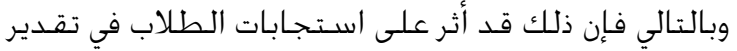

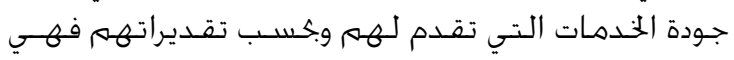

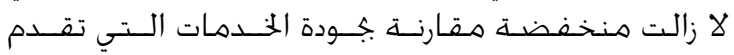

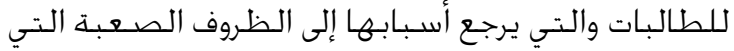

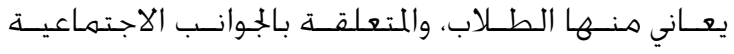

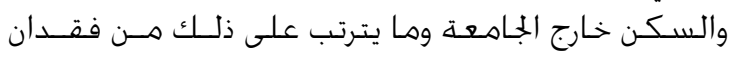

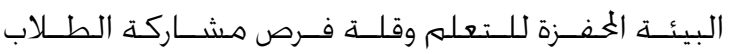

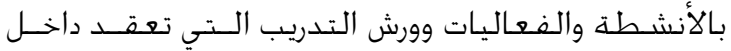

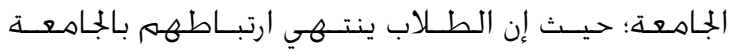

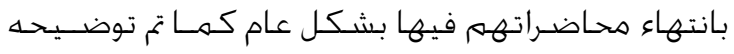

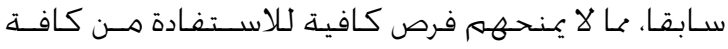

الخدمات التي توفرها عمادة شؤون الطلاب بالجامعة.

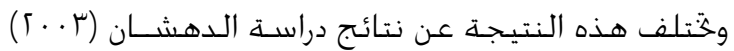

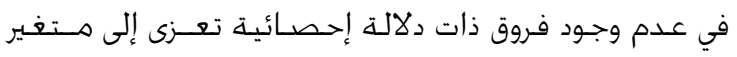

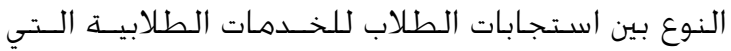

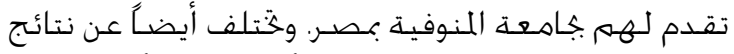

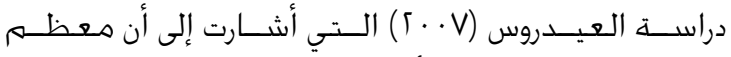

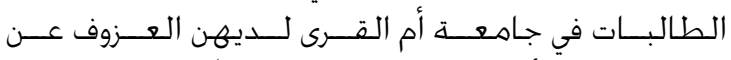

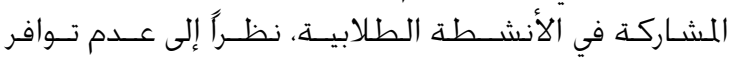

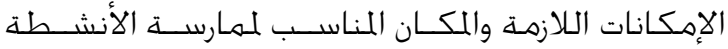
جامعة أم القرى في المملكة العربية السعودية.

متغير السنة الدراسية:

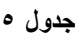

تتائج تحليل التباين المتعدد لاستجابات أفراد عينة الدارسة على جميع مجالاتها وفقاً لمتغير السنة الدارسية.

\begin{tabular}{|c|c|c|c|c|c|c|c|}
\hline 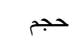 & 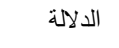 & قيمة "ف" & متوسط & درجة & مجموع & مجالات الدراسة & مصدر التباين \\
\hline الأثر & الإحصائية & المحسوبة & المربعات & الحرية & المربعات & & \\
\hline$\cdot, \cdot r \leqslant$ & $\cdot, \cdot r$ & ¿,qT) & $1,7 \wedge 7$ & $r$ & $0, .0 \mathrm{~V}$ & الخدمات الاجتماعية & السنة الدراسية \\
\hline$\cdot, .11$ & $\cdot, \cdot 1$ & r,vAr & r,IVo & r & 7,0 TY & خدمات الإسكان الطلابي & \\
\hline •, , r & (TוT & $\cdot, 7 \cdot r$ & $\cdot, \leqslant 1$. & r & I,rT. & خدمات التغذية الطلابية & \\
\hline$\cdot, \cdots$ & •,११५ & D & $\cdot, \cdot 10$ & $r$ & $\cdot, \leqslant \uparrow$ & الإرشاد والتوجيه الديني & \\
\hline$\cdot, \cdots 7$ & $\cdot, r 10$ & 1, וAr &., 010 & $r$ & $1,0 \leq \leqslant$ & النشاط الثقافي والفني & \\
\hline$\cdot, \cdots$ & $\cdot, r \vee 4$ & $1, \cdot 47$ & •, & $r$ & $1, \leq \leq 9$ & خدمات النشاط الرياضي & \\
\hline \multirow[t]{8}{*}{$\cdot, \cdot 1 \cdot$} & $\cdot, .90$ & $r, I Y A$ & $1, r \cdot 1$ & r & $r, T r \varepsilon$ & التريب المستدام للطلاب & \\
\hline & & & $\cdot, r \leqslant r$ & 7.7 & $r \cdot V, 1 T$. & الخدمات الاجتماعية & الخطأ \\
\hline & & &., 0 ○o & 7.7 & $r \leqslant \Lambda, \varepsilon \leqslant \wedge$ & خدمات الإسكان الطلابي & \\
\hline & & & $\cdot, \uparrow \wedge$ & 7.7 & $\{11,977$ & خدمات التغذية الطلابية & \\
\hline & & & -, \&Nץ & 7.7 & rq1,qrq & الإرشاد والتوجيه الديني & \\
\hline & & & .,$\leqslant r_{0}$ & 7.7 & rTr,TrV & النشاط الثقافي والفني & \\
\hline & & & 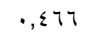 & 7.7 & YAY,ONI & خدمات النشاط الرياضي & \\
\hline & & &., 071 & 7.7 & $r \leq r, q) \leq$ & التدريب المستدام للطلاب & \\
\hline
\end{tabular}


ويمكن تفسير ذلك إلى أن الخدمات الـتي تقــــمها عمــادة

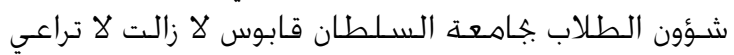

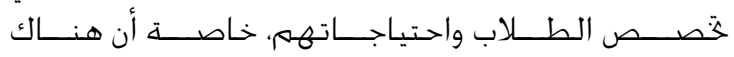

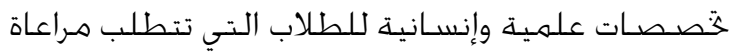

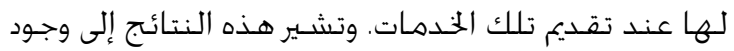

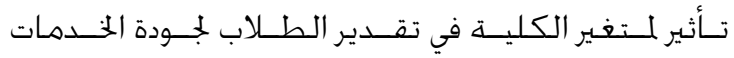

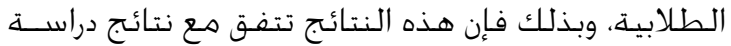

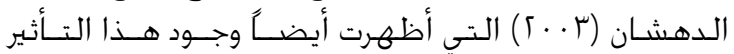

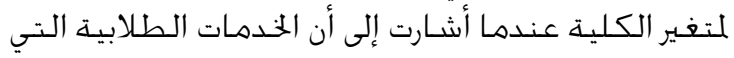

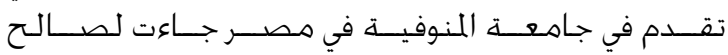
الكليات الإنسانية مقارنة بالكليات العلمية.

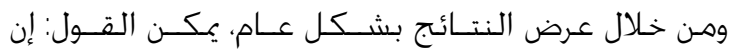

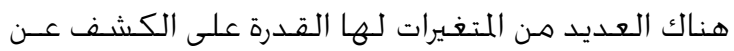

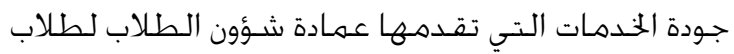

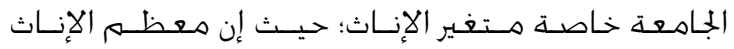

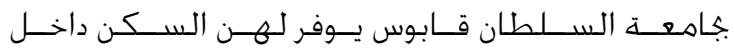

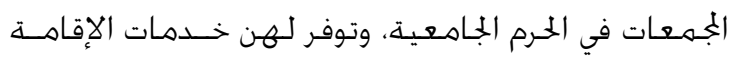

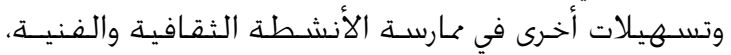

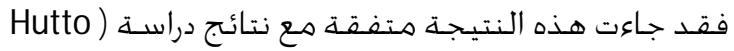

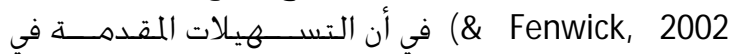

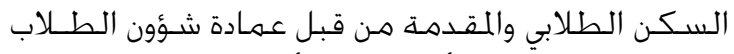

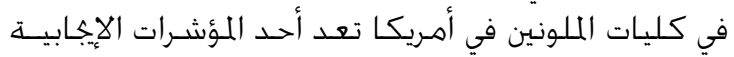

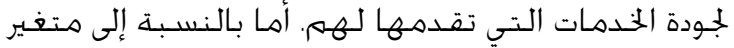

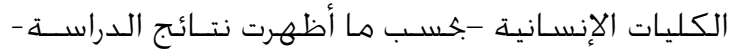

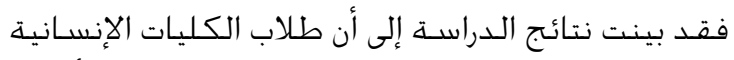

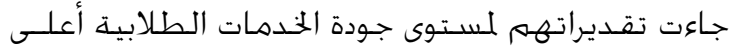

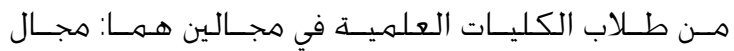

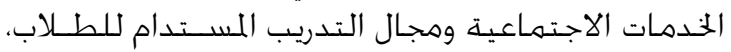

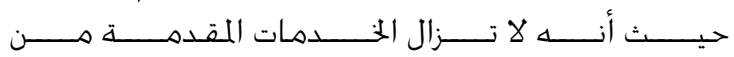

توفرها العمادة والمتعلقة بالإسكان الطلابي، وقد يعـود

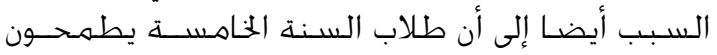

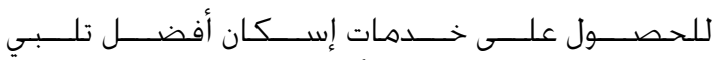

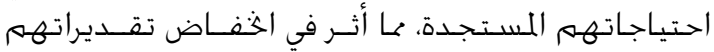

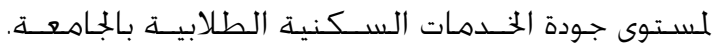

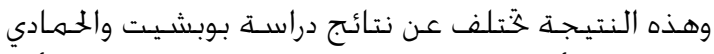

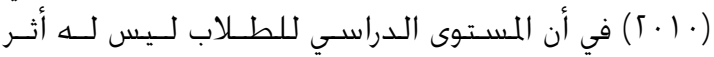

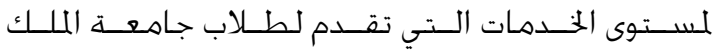
فيصل بالمملكة العربية السعودية.

\section{متغير الكلية:}

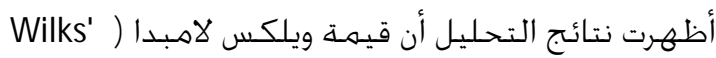

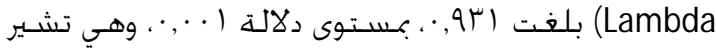

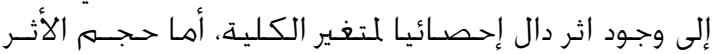

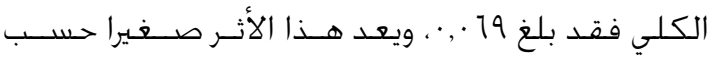

معيار (Cohen, 1988)، كما هو موضسح في جدول 1.

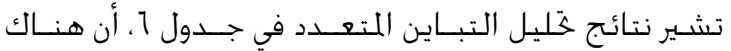

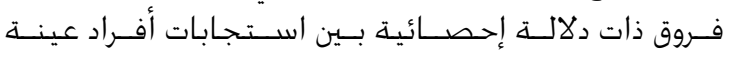

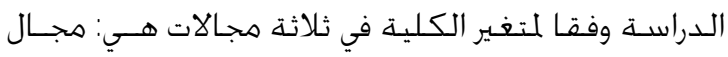

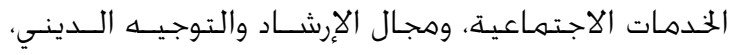

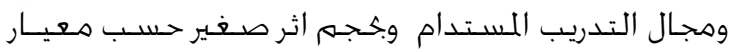

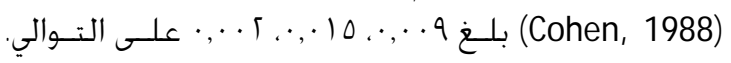

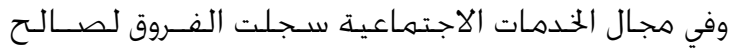

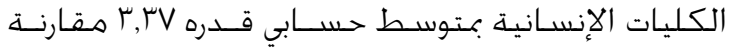

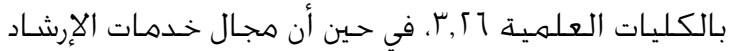

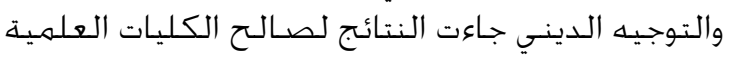

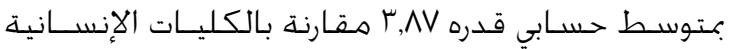

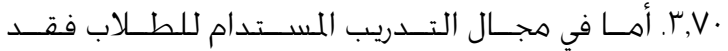

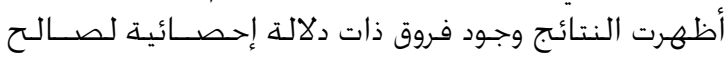

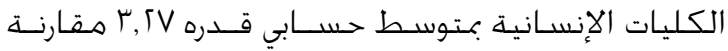
بالكليات العلميـة ه.ر.

جدول 1

نتائج تحليل التباين المتعدد لاستجابات أفراد عينة الدراسة على جميع مجالاتها وفقا لمتغير الكلية

\begin{tabular}{|c|c|c|c|c|c|c|c|}
\hline الأثر & الإلالة & قيمة "ف" المحسوبة & منوسط & درجة & مجموع & مجالات الدراسة & مصدر التباين \\
\hline$\cdot, \cdots 9$ & $\cdot, \cdot r \cdot$ & $0, \varepsilon \cdot \varepsilon$ & $1, \wedge 79$ & 1 & 1,179 & الخدمات الاجتماعية & 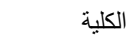 \\
\hline , , r r & , rYo & $1, \varepsilon \vee 7$ & $\cdot, \wedge \%$ & 1 & $\cdot, \wedge \%$ & خدمات الإسكان الطلابي & \\
\hline$\cdot, \cdots 4$ & $\cdot, \cdot 70$ & $r, \varepsilon r r$ & r,rit & 1 & r,rit & خدمات التغذية الطلابية & \\
\hline$\cdot, .10$ & $\cdot, \cdot, r$ & $9, \varphi_{9}$ & $\varepsilon, \Gamma 97$ & 1 & $\varepsilon, \Gamma 97$ & الإرشاد والتوجيه الديني & \\
\hline$\cdot, \cdots$ & $\cdot, \vee \vee १ \wedge$ & $\cdot, .90$ & $\cdot, \cdot r q$ & 1 & $\cdot, \cdot Y q$ & النشاط الثقافي والفني & \\
\hline$\cdot, \cdots)$ & $\cdot, \leqslant 79$ & $\cdot, 0$, & $\cdot, r \leq 7$ & 1 & $\cdot, r \leq Y$ & خدمات النشاط الرياضي & \\
\hline \multirow[t]{8}{*}{.,$\cdot r r$} & $\cdot, \cdots$ & Ir,rso & $\checkmark, \sum \wedge \uparrow$ & 1 & $\vee, \varepsilon \wedge \uparrow$ & التدريب المستدام للطلاب & \\
\hline & & & $\cdot, r \leqslant 7$ & 7.1 & $r \cdot, r \leqslant v$ & الخدمات الاجتماعية & الخطأ \\
\hline & & & . ONT & $7 \cdot 1$ & ros, $11 \leqslant$ & خدمات الإسكان الطلابي & \\
\hline & & & דיר TVו & $7 \cdot 1$ & $\varepsilon 1 \cdot, \wedge \wedge \varepsilon$ & خدمات التغذية الطلابية & \\
\hline & & & $\cdot, \varepsilon \vee \Gamma$ & $7 \cdot 1$ & YAv, OVq & الإرشاد والتوجيه الديني & \\
\hline & & & ד צ & 7.1 & $r 70,1 \leq r$ & النشاط الثقافي والفني & \\
\hline & & & $\cdot, \leq 7 \vee$ & 7.1 & 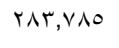 & خدمات النشاط الرياضي & \\
\hline & & & $\cdot, 009$ & 7.1 & $r \varepsilon \cdot, .01$ & التدريب المستدام للطلاب & \\
\hline
\end{tabular}




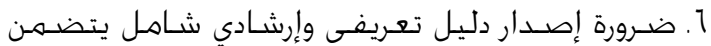

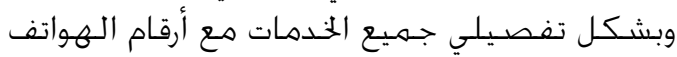

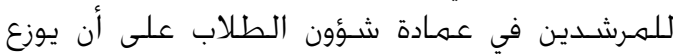
لجميع الطلاب عند الالتحاق بالجامعت.

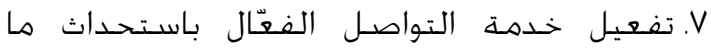

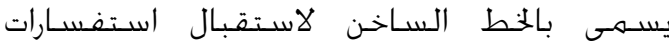

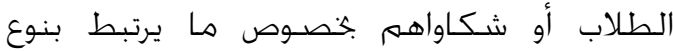
الخدمات التي تقدم لهمهم.

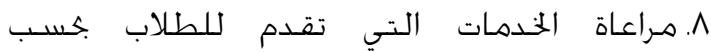

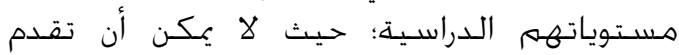

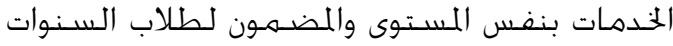

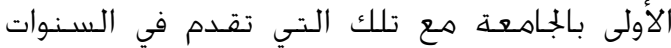

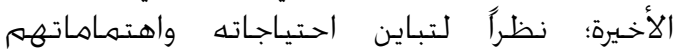
وتوقعاتهم من الخدمات التي تقدم لهـم خلال وجودهم بالجامعتة.

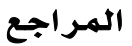

\section{المراجع العربية: - (الم}

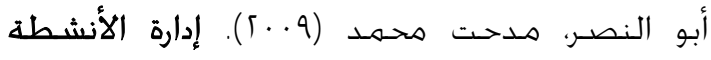
والخدمات الطلابية في المؤسسات التعليمية. القـاهرة: دار الفجر للنشـر والتوزيع.

البلوشي، يوسف بن عبد اللهّ (ب . ـ ؟). المشكلات الإدارية

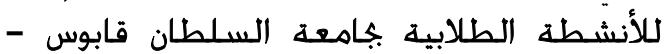
دراسة خليلية. (رسالة ماجستير غير منشـورة)، جامعة السـلطان قابوس.

بوبشيت: الجوهرة إبراهيه: والحمادي، فايزة صالح الحماتح

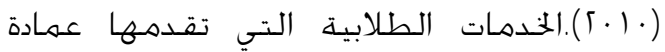

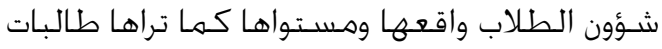

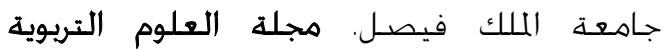

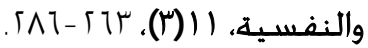

جامعة السلطان قابوس (9 . ؟). الخطة الإستراتيجية

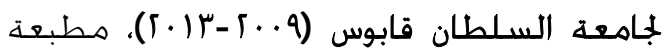
جامعة السـلطان قابوس.

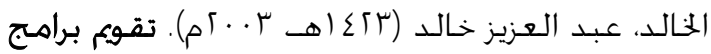
الأنشطة الرياضية بجامعة الملك سعود بالرياض.

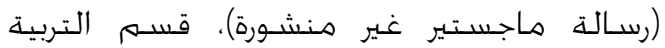
البدنية وعلوم الحركة، كلية التربية، جامعة الملك الكربك

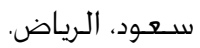

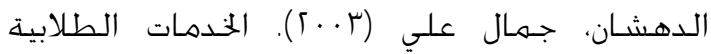

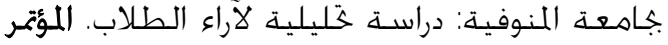
السـوي العاشـر (العربي الثاني) لمركز تطوير التعليم

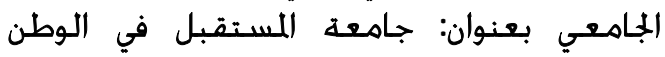
العربي، كلية التربية - جامعة عين شعمس، ديسمبر،

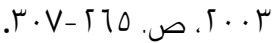

قبل العمادة تلبي رغبات واحتياجات طلاب الكليات

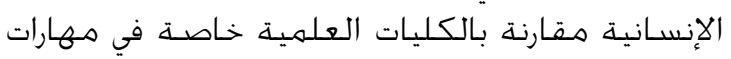
التفكير الناقد وعقد ورش تدريبية في مجال الإبداع

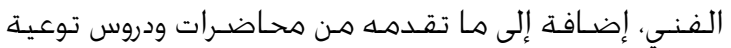

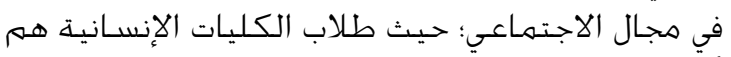

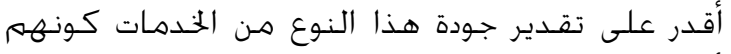
أكثر المشاركين فيها مقارنة بطلاب الكليات العلمية:

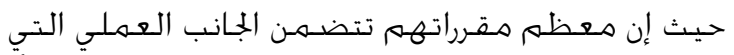

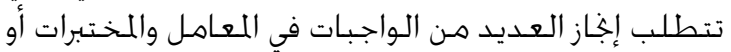

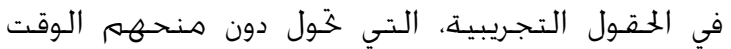

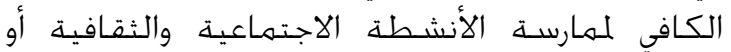

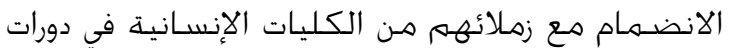

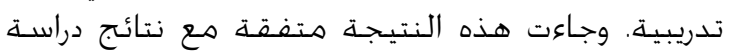

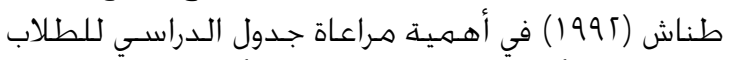

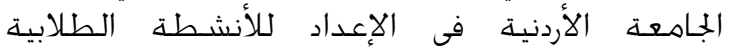

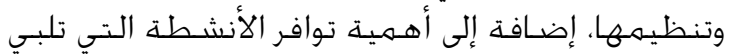

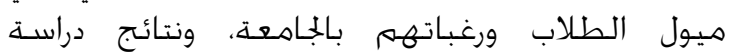

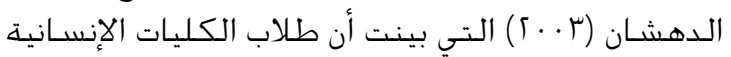

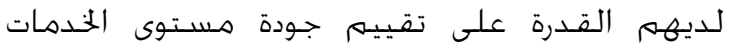

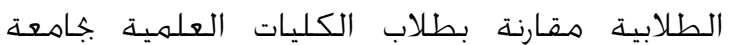

اللنوفيـة بمهـر.

\section{التوصيات و المقترحات:}

ا. ضـرورة مراقبة عملية سـير النظام الغذائي للطلاب

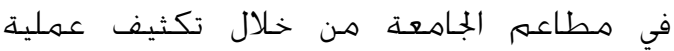

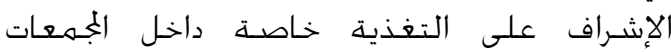
السكنية للطالبات، ومطاعم الطلاب.

آ. ضـرورة تضمين مهام العمادة جزءا يتعلق برعاية

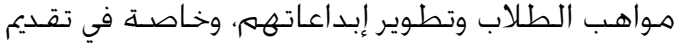

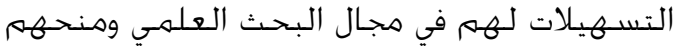

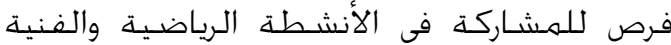
والرحلات الترفيهية.

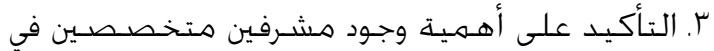

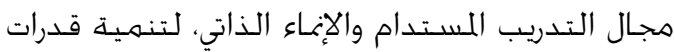

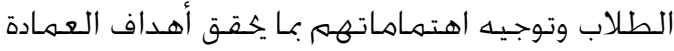

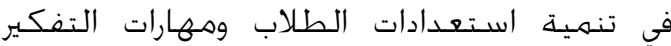
الناقد لديهم بما يرفع من مستوى جودة الخدمات النات التي تقدم لهم للطلاب.

ع. مراعاة تلبية احتياجات الطلاب من الخدمات من قبل لـابل

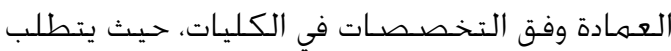

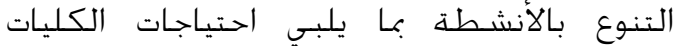

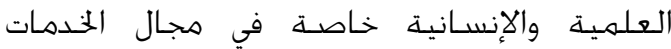
الاجتماعية والتدريب المستدام.

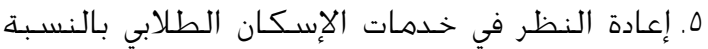

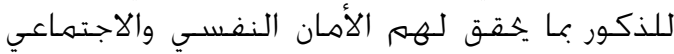

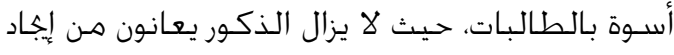
سكن ملائم لهمم خارج الحرم الجامعي. 


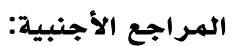

Bresciani, M. L. (2008). Global competencies in student affairs services professionals: A literature synthesis. College Student Journal, 42(3), 906-919.

Cohen, J. (1988). Statistical power analysis for the behavioral sciences, (2nd ed.). New Jersey: Lawrence Erlbaum.

Cutler, H. A. (2002). Student affairs program in counselor education: past, present and future. (ERIC NO: ED 467344).

Hemphill, B. O., \& LaBanc, B. H. (2010). Enough is enough. Sterling, Virginia, USA: Stylus Publishing LLC,

Hutto, C. P.; \& Fenwick, L. T. (2002). Staying in college: student services and freshman retention at historically black colleges and universities (HBCUs). Report- Research, (ERIC NO: ED 468397)

Kezar, A. (2003). Student affairs administrators: Building collaborations with students and academic affairs for institutional improvement. $\mathrm{N}$ ational Roundtable Series (ERIC NO:ED 482218).

Mattox, R. E.; \& Creamer, D. G. (1998). Perceptions of the scope and quality of student services functions in two-year colleges. Community Coll ege Review, 25(4), 3-18. (ERIC NO:EJ 564351)

Pearson, F. C.; \& Collins, W. R. (2001). Senior student affairs officers' perceptions of campusbased student religious organization (CBSRO). Paper presented at the annual meeting of the $\mathrm{N}$ ational Association of Student Personnel A dministrators, 83rd, Seattle, WA, March, 17-21, 2001, (ERIC NO:ED 455176).

Whitt, E. J. (2005). Promoting student success: what student affairs can do? Occasional Paper no. 5, Bloomington, Indiana: Indiana University Center for Postsecondary Research.
زايد، كاشـف؛ والجبالي، مصـفي؛ والشـعيلي، علي

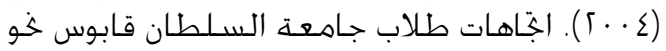

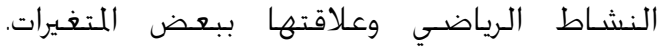

سلسـلة الدراسـات النفسية والتربوية، كلية التربية

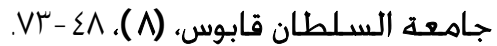

زيدان، هـراد صالح مراد (1991). مـدى خَقيق الجاهعات

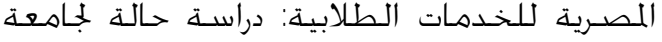

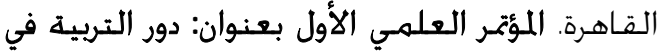

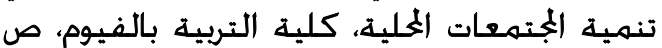
$.0 T V-\Delta \Gamma T$

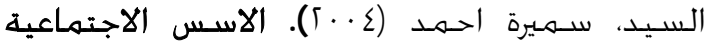

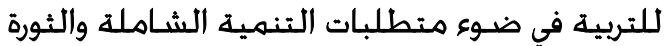

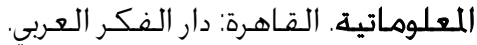

طناش، سـلامة (1995). الأنشـطة الطلابية في الجامعة

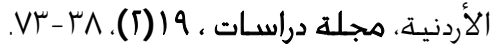

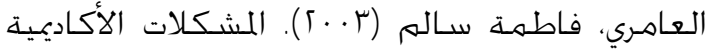

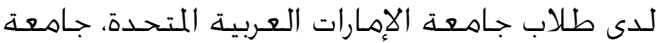

الإمارات العربية. مجلة كلية التربية، 1|( • ؟)، 9 || | $.1 \wedge \mu$

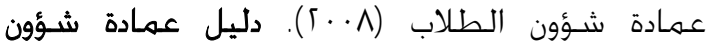
الطلاب. جامعة السلطلان قابوس.

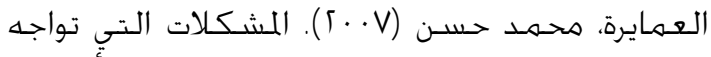

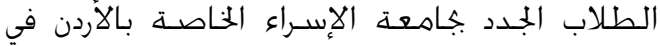

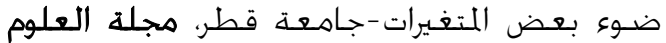

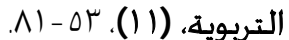

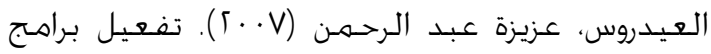

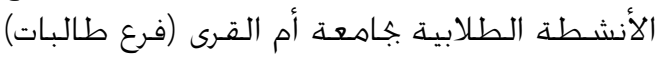

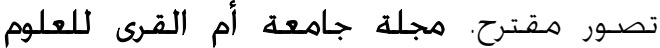

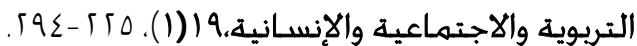

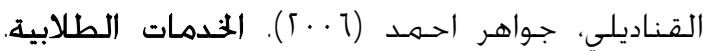

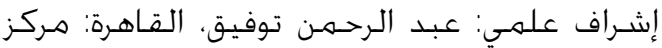
الخبرات المهنيـة للإدارة، بميك.

كيوة، جورج د.؛ كينزي، جيليان؛ اتش -توتش، جون؛ ويت

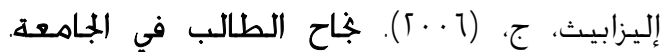

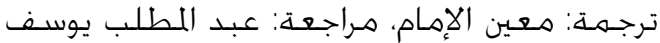
جابر، الرياض: مكتبة العبيكان.

متولي، ماجدة سـعد (991)). تقـدير جودة الخدمات

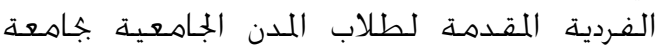

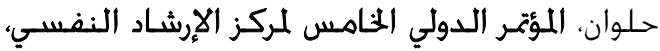

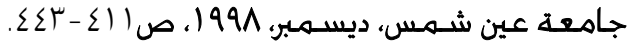


ملحق 1

المتوسطات الحسابية والانحرافات المعيارية والرتب لاستجابات أفراد عينة الدراسة التي حصلت على مستوى "متوسط" على جميع مجالاتها

\begin{tabular}{|c|c|c|c|c|}
\hline الالحعراف & الحسابي & 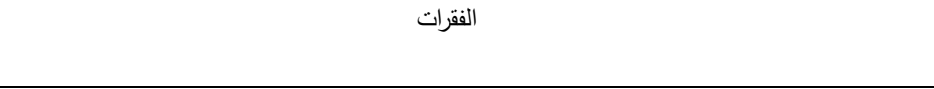 & 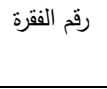 & 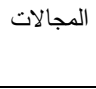 \\
\hline$\cdot, 94$ & $r, \leqslant 0$ & تتميز الأساليب التي تتبعها العمادة للترويج لأنشطتها بين الطلاب بالتجديد والحيوية. & r & \multirow{9}{*}{$\begin{array}{l}\bar{y} \\
3 \\
\overline{3} \\
\overline{7} \\
. \overline{3} \\
\frac{9}{y}\end{array}$} \\
\hline$\cdot, 9 \leqslant$ & $r, \leq \varepsilon$ & تشجع أنشطة العمادة على العمل بروح الفريق الواحد لتوطيد معاني التكافل والتعاون . & ir & \\
\hline$\cdot, 94$ & $r, \leqslant$ & تنفذ خمات العمادة الاجتماعية وفق خطة واضحة. & 1 & \\
\hline 1,10 & $r, r v$ & تتابع العمادة بالتعاون مع عمادة القبول والتسجيل حالات الطلاب الذين ينجاوز غيابهم الحد المسموح به. & 1 & \\
\hline$\cdot, 9 \cdot$ & $r, r \cdot$ & تتعاون العمادة بفاعلية مع مؤسسات المجتمع المحلي التي تقام خدمات للطلاب. & ir & \\
\hline $1, \cdot 9$ & $r, 19$ & تتابع العمادة حالات الطلاب المتعثرين دراسيا. & $\mathrm{v}$ & \\
\hline $1, \cdots$ & $r, 1 \leq$ & تتسق العمادة مع مركز الإرشاد الطلابي لمعالجة المشكلات النفسية للطلاب . & 11 & \\
\hline $1, .9$ & $r, .0$ & تتابع العمادة خدمة الرعاية الصحية (عيادة الطلاب) والعيادات داخل المجمعات السكنية . & 1. & \\
\hline $1, \cdot 1$ & זיז & تقوم العمادة بتتفيذ رحلات وزيارات لمعالم السلطنة. & $\circ$ & \\
\hline $1, \cdot \varepsilon$ & $r, \varepsilon r$ & تضع العمادة لوائح وتعليمات لتتظيم حياة الطلاب في الإسكان الداخلي . & 10 & \multirow{6}{*}{ 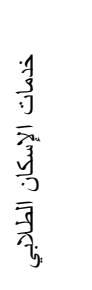 } \\
\hline I,ir & $r, r v$ & تعمل العمادة على تسهيل تسكين الطلاب في بداية العام الدراسي. & $1 \varepsilon$ & \\
\hline $1, \cdot \varepsilon$ & $r, 19$ & تثترف العمادة على سير الحياة اليومية للطلاب بالإسكان الداخلي . & 17 & \\
\hline $1, \cdot 7$ & r,1т & توفر العمادة احتياجات الطلاب في الإسكان الداخلي. & 19 & \\
\hline $1, \cdot 1$ & r,l. & تتابع العمادة الطلاب غير الملتزمين باللوائح والتعليمات الخاصة بالإسكان الجامعي. & 11 & \\
\hline $1, \cdot r$ & r,१५ & تقدم العمادة المساعدة لمعالجة المشكلات الاجتماعية التي تعيق تكيف الطلاب في الحياة الجامعية. & iv & \\
\hline $1, \cdot v$ & r, , ० & تعمل العمادة على تفعيل لجان التغذية الطلابية للمساهمة في التوعية الغذائية. & $r \varepsilon$ & \multirow{5}{*}{ 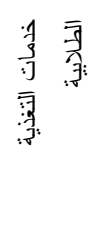 } \\
\hline $1, \cdot 9$ & $r, Y)$ & تقوم العمادة بالإشراف على خدمات التغذية المقدمة للطلاب . & rt & \\
\hline $1,1 \leq$ & $r, \mathrm{r} \cdot$ & تعمل العمادة على مراقبة المواصفات والمقاييس الصحية للتغذية المقدمة للطلاب . & r. & \\
\hline 1,10 & r,OV & تتميز الوجبات الغذائية المقدمة للطلاب بالتتوع. & ro & \\
\hline 1,17 & $r, 01$ & تتميز خدمات التظذية الطلابية بالجودة والمتابعة المستمرة. & r) & \\
\hline I, Ir & $r, \varepsilon r$ & توفر العمادة قاعات مناسبة لممارسة الألعاب الترفيهية للطلاب (بلياردو ، تتس، البولنج ... الخ) . & « & \multirow{5}{*}{ 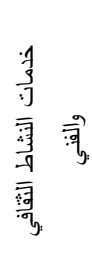 } \\
\hline$\cdot, 90$ & $r, \varepsilon \cdot$ & تقييم العمادة مسابقات علمية بين الطلاب. & $\varepsilon r$ & \\
\hline 1,11 & r, rq & تنظم العمادة الرحلات الطلابية السنوية . & $\varepsilon$ & \\
\hline $1, \cdot v$ & r, r & ترعى العمادة مواهب الطلاب وتتميها . & rv & \\
\hline $1, \cdot 7$ & r,TV & تنظم العمادة زيارات للطلاب إلى الجامعات العربية والأجنبية . & צ & \\
\hline$\cdot, 9$ & $r, \imath \wedge$ & تنظم العمادة احتفالات تكريم الطلاب المتفوقين في الأنشطة الرياضية . & 01 & \multirow{4}{*}{ 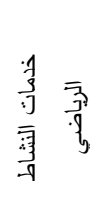 } \\
\hline $1, \cdot 7$ & $r, \varepsilon \vee$ & توفر العمادة أماكن التسلية والترفيه الرياضي لطلاب الجامعة . & $\varepsilon v$ & \\
\hline$\cdot, 99$ & $r, \leqslant 0$ & تقيم العمادة أنشطة رياضية ودية مع فرق رياضية من خارج الجامعة . & $\leq 7$ & \\
\hline$\cdot, 90$ & $r, r \cdot$ & تجري العمادة الفحوصات والاختبارات اللازمة لطلاب التفوق الرياضي . & ○. & \\
\hline $1, \cdot 1$ & ז ד & تقوم العمادة بنشر الوعي الرياضي بين الطلاب . & $\varepsilon r$ & \multirow{9}{*}{$\begin{array}{l}\overline{\text { 可 }} \\
\overline{\bar{g}} \\
\frac{\overline{3}}{2}\end{array}$} \\
\hline $1, \cdots$ & $r, r v$ & تنظم العمادة محاضرات علمية. & 07 & \\
\hline $1, \cdot 1$ & $r, r v$ & تعقد العمادة دورات تدريبية تلبي احتياجات الطلاب في مهارات الحاسوب. & or & \\
\hline$\cdot, 9 \vee$ & $r, r$ & تساهم الخدمات التي تقدمها العمادة إلى توفير بيئة محفزة للتعلم . & 00 & \\
\hline$\cdot, 99$ & $r, 17$ & تقيم العمادة ورش تدريبية في مجال الإبداع الفني. & $0 \leqslant$ & \\
\hline $1, \cdot 1$ & $r, 17$ & تعقد العمادة دورات تدريبية تلبي احتياجات الطلاب في مهارات اللغة . & 01 & \\
\hline $1, \cdot v$ & r,l. & تعقد العمادة دورات تدريبية تلبي احتياجات الطلاب في مهار ات الاتصال. & 09 & \\
\hline $1, .0$ & r, 94 & تعمل العمادة على أن تكون الفترة الزمنية للاورات التنرييية الطلابية متتاسبة مع جدولهم الدراسي . & or & \\
\hline $1, \cdot r$ & ५,१५ & تعقد العمادة دورات تدريبية للطلاب في مهارات التفكير الناقد. & or & \\
\hline
\end{tabular}




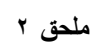

المتوسطات الحسابية والانحرافات المعيارية لاستجابات أفراد عينة الاراسة حسب متغيراتها

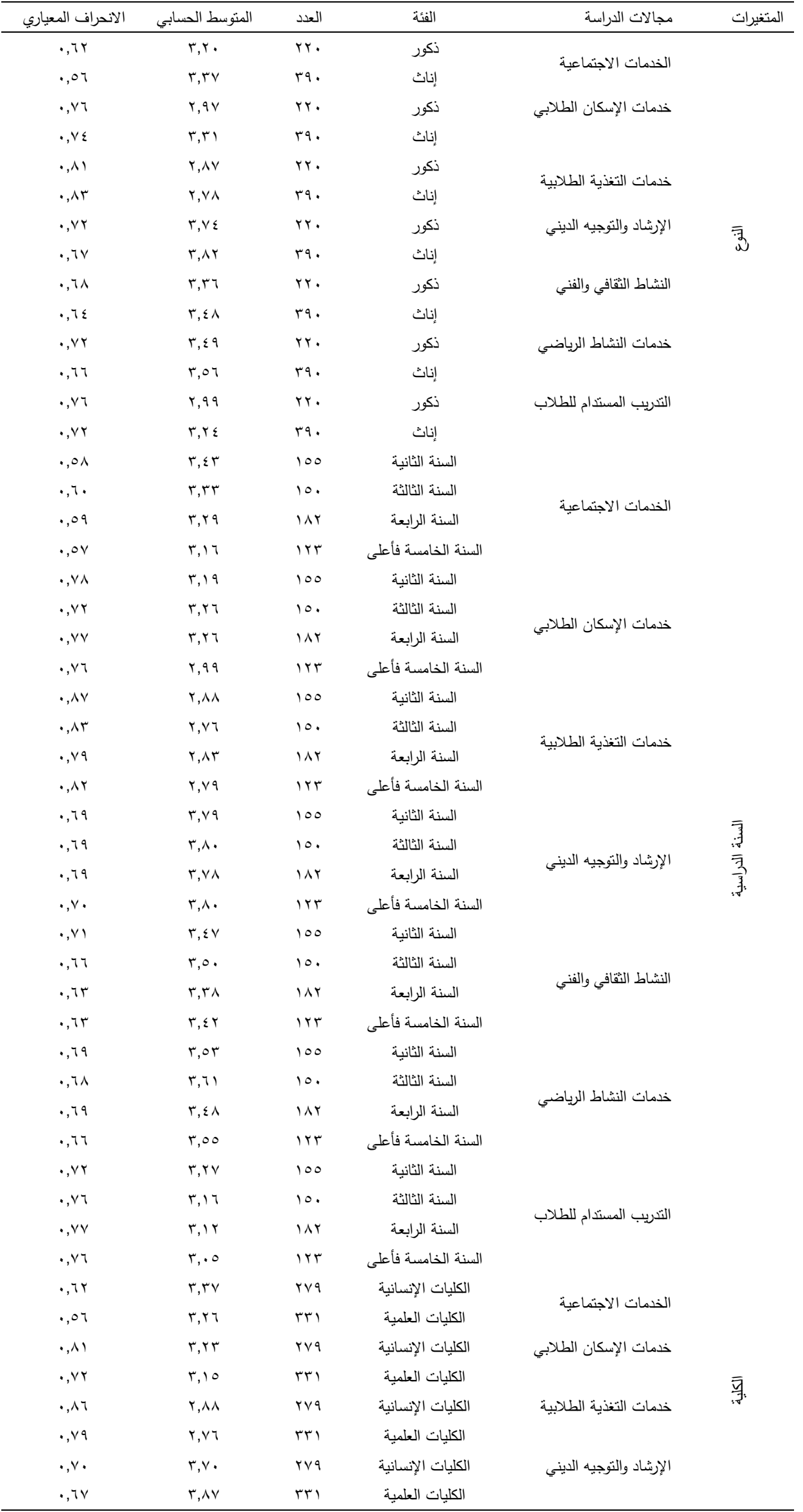




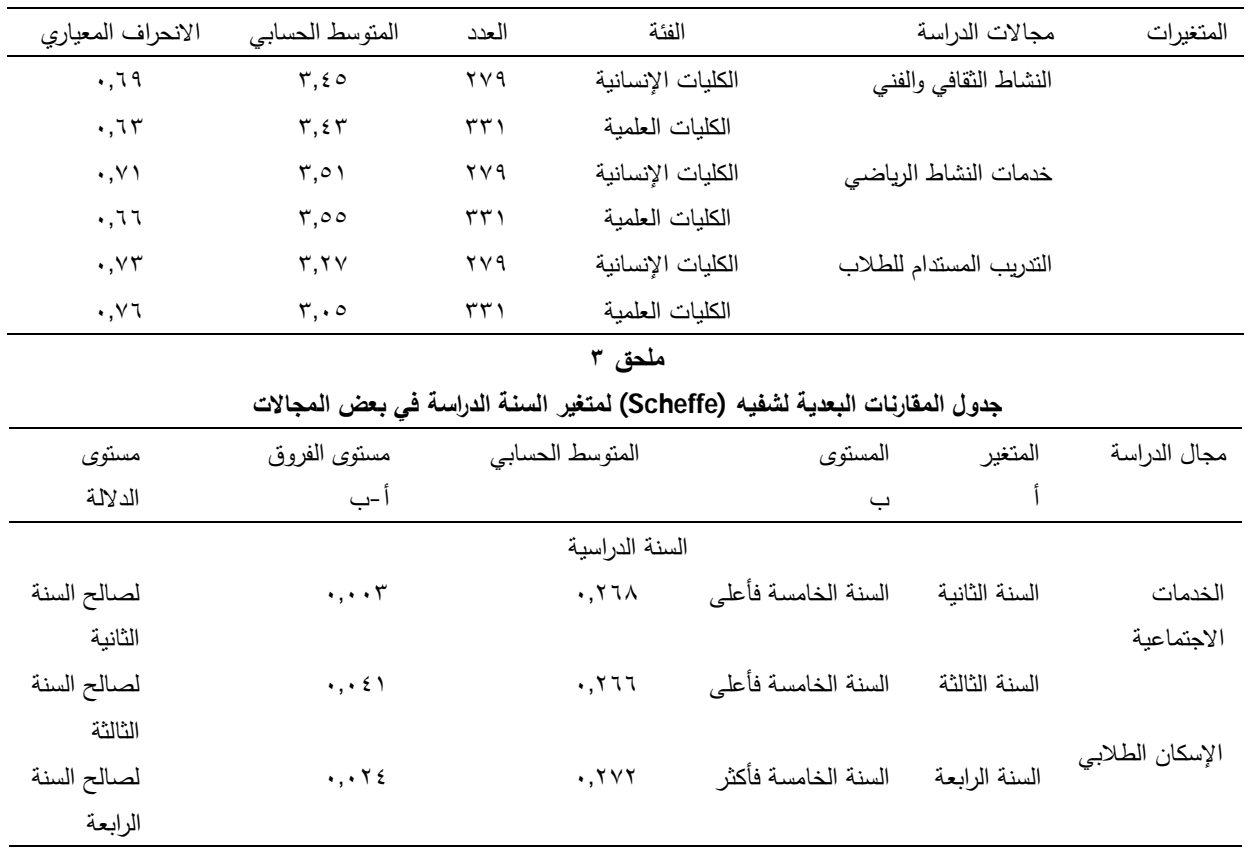

